\title{
LA EXTINCIÓN DE LAS FUNDACIONES POR IMPOSIBILIDAD DE REALIZACIÓN DEL FIN FUNDACIONAL
}

\author{
M. ${ }^{a}$ Isabel CADENAS GARCÍA \\ Abogada del Estado \\ isabel.cadenas@mecd.es \\ Óscar SÁEnz de Santa María GÓmez-Mampaso \\ Abogado del Estado \\ oscar.saenz@mecd.es
}

\begin{abstract}
RESUMEN
El adecuado estudio de esta causa de extinción requiere el examen previo de qué se entiende por fundación y del régimen jurídico al que las mismas se someten, para a continuación, y partiendo de tales premisas, relacionar esta causa con las restantes de extinción, analizar cuándo concurre la imposibilidad de realización del fin fundacional, cuáles son los requisitos que la aplicación de la misma exige y sus consecuencias o, lo que es lo mismo, la liquidación una vez acordada la extinción.
\end{abstract}

Palabras clave: extinción, fundaciones, imposibilidad, fin fundacional.

\section{ABSTRACT}

An appropriate study of this extinguishment requires first the examination of how foundation is construed and of the legal system to which they are subject, in order, based on those principles, to relate this cause with the remaining causes of extinguishment, analyze what the requirements which the application thereof demands are and their consequences or, in other words, liquidation once extinguishment has been agreed.

Keywords: extinguishment, foundations, impossibility, founding purpose.

\section{ZUSAMMENFASSUNG}

Die sachgemäße Untersuchung der Gründe für das Erlöschen von Stifungen erfordert zunächst eine vorausgehende Untersuchung dessen, was man als Stiftung versteht und eine Analyse der Rechtsform, der sie unterworfen ist.. Ausgehend von diesen Prämissen werden diese in Beziebung gesetzt zu den weiteren Gründen des Erlöschens der Stiftungen, wie die Unmöglichkeit der Verwirklichung des Stiftungszwecks. Es wird untersucht, welche Anforderungen der Stiftungszweck an die Stiftung stellt und seiner Konsequenzen, die die Abwicklung betreffen, nachdem die Auflösung vereinbart wurde.

Schlüsselwörter: Erlöschen, Stiftungen, Unmöglichkeit, Stiftungszweck. 
SUMARIO: I. INTRODUCCIÓN.-II. CONCEPTO DE FUNDACIÓN.-1 . Organización.-2. Sin fin de lucro.-3. Afección duradera de su patrimonio a la consecución de fines de interés general.-III. RÉGIMEN JURÍDICO DE LAS FUNDACIONES.-1. La voluntad del fundador.-2. Los estatutos.-3. La Ley.-IV. EXTINCIÓN DE LAS FUNDACIONES. CLASIFICACION DE LAS CAUSAS.-1. Clasificación realizada por nuestros Tribunales de Justicia.-2. Clasificación defendida por la doctrina.-V. EXTINCIÓN DE LAS FUNDACIONES POR IMPOSIBILIDAD DE REALIZACIÓN DEL FIN FUNDACIONAL.-1. Casos en que concurre la imposibilidad de realización del fin fundacional.-2. Requisitos necesarios para que opere esta causa de extinción.-3. Intervención del protectorado.- - 4. Intervención de la autoridad judicial.-VI. LIQUIDACION DE LAS FUNDACIONES.-1. Destino de los bienes y derechos resultantes de la liquidación.-2. Procedimiento de liquidación y criterios reguladores del procedimiento de liquidación.-VII. CONCLUSIONES.

\section{INTRODUCCIÓN}

Las fundaciones nacen con vocación de permanencia, o, por lo menos, de cumplir su finalidad, objetivo éste propio de las fundaciones temporales que se extinguen por la llegada del tiempo por el que fueron constituidas por plazo o del que se confirieron para acometer un fin concreto de interés general, de manera que la imposibilidad de realización del fin fundacional se recoge en nuestro ordenamiento jurídico como una causa propia de extinción de las fundaciones.

La doctrina ${ }^{1}$ pone de manifiesto que, de acuerdo con los datos de que se disponía a fecha 31 de diciembre de 2005, había 8.419 fundaciones registradas en los 84 protectorados existentes en la Administración Central del Estado y en las 17 Comunidades Autónomas, de las que se estima que 6.047 estaban activas, lo que supone una tasa de inactividad del 28 por 100 , y un número de fundaciones vivas muy superior al que se estimó para 2001 en el primer estudio realizado en España con el objetivo de estimar las macromagnitudes del tercer sector, en el que dicha tasa era superior al 65 por 100 .

La tasa de inactividad es, aun así, lo suficientemente significativa para que se aborde en este artículo el estudio de las circunstancias que determinan que las fundaciones inactivas no puedan realizar el fin fundacional y puedan, en consecuencia, extinguirse.

1 J. L. García Delgado, Á. Triguero Cano y J. C. Jiménez Jiménez, Fundaciones. Problemas actuales y reforma legal, Navarra-Principado de Asturias, Aranzadi-Fundación María Cristina Masaveu Peterson, 2011, pp. 166 y 167. 
El examen de las circunstancias que determinan que las fundaciones no puedan realizar el fin fundacional, o, en otras palabras, que determinan la imposibilidad de realización del fin fundacional, se aborda en el correspondiente apartado de este estudio, al que preceden el que se refiere a la obligada definición del concepto de fundación con relación a la cual opera esta causa de extinción; el régimen jurídico al que se someten las fundaciones, en concreto, los instrumentos por los que se rige la vida jurídica de las fundaciones que recogen esta causa de extinción de las mismas, y su relación, en el marco de las clasificaciones establecidas por los Tribunales de Justicia y la doctrina, con las restantes causas de extinción de las fundaciones.

Prosigue el estudio con el examen de los requisitos establecidos en la normativa aplicable para que pueda operar la causa de extinción que nos ocupa, dedicando apartados específicos a la intervención del protectorado y de la autoridad judicial, y al examen de las consecuencias de la extinción que opera por esta causa, esto es, la liquidación una vez acordada la extinción de las fundaciones.

\section{CONCEPTO DE FUNDACIÓN}

La imposibilidad de realización del fin fundacional puede dar lugar a la extinción de las fundaciones según el concepto de las mismas recogido por la normativa vigente, por nuestros Tribunales de Justicia y por la doctrina.

El concepto tradicional de fundación se recoge por nuestros Tribunales de Justicia, pudiendo citarse, dado el engarce constitucional de estas entidades, la Sentencia del Tribunal Constitucional 18/1984², de 7 de febrero, que indica que el art. $34 \mathrm{CE}$ se refiere sin duda al concepto de fundación admitido de forma generalizada entre los juristas y que considera la fundación como la persona jurídica constituida por una masa de bienes vinculados por el fundador o fundadores a un fin de interés general. La fundación nace, por tanto, de un acto de disposición de bienes que realiza el fundador, quien los vincula a un fin por él determinado y establece las reglas por las que han de administrarse, al objeto de que sirvan para cumplir los fines deseados de manera permanente o, al menos, duradera. Tanto

${ }^{2}$ Recogida, por todas, en la Sentencia del Tribunal Superior de Justicia de Cantabria de 19 de septiembre de 2002 (RJCA 2002\786). 
la manifestación de voluntad como la propia organización a crear han de cumplir los requisitos que marquen las leyes, las cuales prevén, además, un tipo de acción administrativa (el protectorado) para asegurar el cumplimiento de los fines de la fundación y la recta administración de los bienes que la forman.

Verdera $^{3}$ destaca que el art. 2.1 de la Ley 50/2002, de 26 de diciembre, de Fundaciones, identifica las fundaciones con las «organizaciones constituidas sin fin de lucro que, por voluntad de sus creadores, tienen afectado de modo duradero su patrimonio a la realización de fines de interés general». Dicho precepto parte del respeto al concepto de fundación que comenzaba ofreciendo la anterior Ley 30/1994, de 24 de noviembre, de Fundaciones ${ }^{4}$, y se enmarca claramente en el molde clásico elaborado por los Tribunales de Justicia, en el sentido de que por medio del ejercicio del derecho de fundación se produce la afectación de un patrimonio ${ }^{5}$, si bien con el matiz que supone la constitución de una organización dotada de personalidad jurídica, lo cual significa la acogida de un concepto más actual ${ }^{6}$.

La mayor parte de las leyes autonómicas ${ }^{7}$ que incorporan el concepto de las fundaciones incluidas en su ámbito de aplicación vienen a definir-

\footnotetext{
3 R. Verdera Server en el libro de J. Olavarría Iglesia (coord.), Comentarios a la Ley de Fundaciones, Valencia, Tirant lo Blanch, 2008, pp. 78 y 79.

${ }^{4}$ La Sentencia de la Sala de lo Contencioso-Administrativo del Tribunal Supremo de fecha 27 de abril de 2005 (Ar. 4557) afirma que: «La Ley 30/1994, de 24 de noviembre (RCL 1994, 3273), de fundaciones y de incentivos fiscales a la participación privada en actividades de interés general [...] pretendió acomodar la regulación de las fundaciones a la Constitución y a la actual distribución de competencias entre el Estado y las Comunidades Autónomas unificando el régimen aplicable a todas ellas. No conviene olvidar que el derecho a crear fundaciones, reconocido en el art. 34 de la Constitución (RCL 1978, 2836), constituye una figura jurídica propia del Derecho civil. Se parte del art. 37 y concordantes como piedra angular del Derecho privado de fundaciones y, por ende, de la jurisdicción civil como la esencial para enjuiciar su actividad. La excepción radica en que la actividad de protectorado ejercido por la Administración, tras la inscripción en el pertinente Registro de Fundaciones, son actos que tienen naturaleza administrativa poniendo fin a la citada vía y, en consecuencia, abriendo su impugnabilidad ante el orden jurisdiccional contencioso-administrativo».

5 R. VERDERA SERVER, op. cit., p. 86.

${ }^{6}$ Ibid., p. 95.

7 Por citar algunos ejemplos: (i) la Ley 10/2005, de 31 de mayo, de Fundaciones de la Comunidad Autónoma de Andalucía, establece, en su art. 1.2, que: «Son fundaciones las organizaciones constituidas sin ánimo de lucro y que, por voluntad de sus creadores, tienen afectado de modo duradero su patrimonio a la realización de fines de interés general»; (ii) la Ley 12/2006, de 1 de diciembre, de Fundaciones de Interés gallego, dispone, en su art. 2.1, que: «Son fundaciones de interés gallego aquellas organizaciones constituidas sin fin de lucro que, por voluntad de sus creadores, tengan afectado de modo duradero su patrimonio a la realización de fines de interés general para Galicia y desarrollen principalmente sus activida-
} 
las de manera semejante a la ley estatal, si bien algunas de ellas ${ }^{8}$ recogen el concepto tradicional, que destaca especialmente la afectación del patrimonio al cumplimiento de fines de interés general y por ello las definen como «personas jurídicas resultantes de afectar permanentemente por voluntad de sus fundadores un patrimonio al cumplimiento de fines de interés general sin ánimo de lucro».

Según la doctrina ${ }^{9}$, del planteamiento legal que recoge el concepto más actual se desprenden, fundamentalmente, los siguientes elementos, que desarrollamos en las subsiguientes líneas: organización, sin fin de lucro, afección duradera de su patrimonio al logro de fines de interés general.

\section{Organización}

La doctrina ${ }^{10}$ pone de manifiesto que el elemento de la organización, esto es, la configuración de la fundación como organización, resulta esencial en la fundación, en cuanto que es persona jurídica que, como tal, precisa de unos órganos que la representen y desarrollen su actividad para la consecución de los fines de interés general definidos por el fundador.

des y tengan su domicilio en el territorio de la Comunidad Autónoma»; (iii) la Ley 1/2007, de 12 de febrero, de Fundaciones de La Rioja, las define, en su art. 1.2, como: «Las organizaciones constituidas por voluntad de sus creadores no tendrán ánimo de lucro y su patrimonio quedará afectado de modo duradero a la realización de fines de interés general».

${ }^{8}$ En este sentido: (i) Ley 2/1998, de 6 de abril, de Fundaciones de Canarias, que, en su art. 1.1, establece que: «A los efectos de esta Ley, son fundaciones las personas jurídicas resultantes de afectar permanentemente por voluntad de sus fundadores un patrimonio al cumplimiento de fines de interés general sin ánimo de lucro»; (ii) Ley 4/2008, de 25 de abril, por la que se aprueba el Libro Tercero del Código Civil de Cataluña, define las fundaciones como las «entidades sin ánimo de lucro, constituidas por uno o varios fundadores, mediante la afectación de unos bienes o de unos derechos de contenido económico y el destino de sus rendimientos o de los recursos obtenidos por otros medios al cumplimiento de finalidades de interés general».

9 R. VERDERA SERVER, op. cit., pp. 78 y 79.

${ }^{10} \mathrm{M} .{ }^{a}$ L. Ortiz Vaamonde, Fundaciones. Cien preguntas clave y sus respuestas, Madrid, Dykinson, 2002, pp. 23 y 24, que explica que «como en toda persona jurídica, la organización es necesaria en la fundación, que, al carecer de base física, necesita de unos órganos que la gestionen y representen. La organización se aglutina alrededor del patrimonio, cuya personalidad jurídica es independiente de esos órganos de gobierno». T. GonZÁlez Cueto, Comentarios de la Ley de Fundaciones. Ley 50/2002, de 26 de diciembre, Navarra, Aranzadi, 2003, p. 51, destaca que «la organización es esencial en cualquier persona jurídica, implica un conjunto de elementos personales y materiales estructurados y articulados para la consecución de un fin definido por el fundador. No cabe duda que los elementos personales son esenciales, porque sirven especialmente para formar la voluntad de la persona jurídica y para exteriorizarla, permitiéndole actuar en el tráfico jurídico y participar activamente en la vida social». 
La organización implica un conjunto de elementos personales aglutinados alrededor del patrimonio a quienes corresponde administrar con diligencia los bienes y derechos que integran el patrimonio de la fundación, manteniendo el rendimiento y utilidad de los mismos para cumplir los fines fundacionales (art. 14.2 de la Ley de Fundaciones). El órgano de gobierno y representación de la fundación es el patronato, que adoptará sus acuerdos por mayoría en los términos establecidos en los Estatutos (art. 14.1 de la Ley de Fundaciones). La propia Exposición de Motivos de la Ley de Fundaciones pone de manifiesto que en el Capítulo III de la misma se potencia la estabilidad y adecuado funcionamiento de los órganos de gobierno de las fundaciones con la obligatoriedad de la figura del secretario y con la posibilidad de crear órganos distintos del patronato para el desempeño de los cometidos que expresamente se le encomienden. Debemos, no obstante, destacar que la configuración de la fundación como organización - o lo que es lo mismo, de las personas en torno a ese patrimonio designadas para su gestión- es cuestión distinta a la de su personalidad jurídica, que es independiente de sus órganos de gobierno.

\section{Sin fin de lucro}

La Sentencia del Tribunal Superior de Justicia de Andalucía (Sevi1la) de fecha 15 de febrero de 2001 (JT 2001\1152) define el ánimo de lucro como un concepto propio del Derecho mercantil, que se caracteriza por el destino que va a dar una determinada entidad a las ganancias o, dicho de otro modo, al incremento patrimonial derivado del ejercicio de su actividad, destino que es el reparto, la distribución entre los socios o propietarios de aquélla; por consiguiente, lo propio del ánimo de lucro, conforme se configura por la jurisprudencia, no es el hecho de obtener beneficios, o que éstos se obtengan mediante precio, sino más bien el destino de tales beneficios, que ha de ser la distribución entre los propietarios de la correspondiente entidad, y si tal fin no existe, entonces ya no podrá hablarse de ánimo de lucro.

García-Andrade ${ }^{11}$ acoge el mismo concepto de ánimo de lucro y destaca que el elemento de la ausencia de fin de lucro en las fundaciones tiene

${ }^{11}$ J. García-Andrade Gómez, en el libro de S. Muñoz Machado, M. Cruz Amorós y R. DE LoRenzo García (dirs.), Comentarios a las Leyes de Fundaciones y de Mecenazgo, Madrid, Fundación ONCE, 2005, p. 38, afirma que: «El sentido de imponer que las fundaciones sean constituidas sin fin de lucro es impedir un reparto de las ganancias o de los bie- 
como finalidad impedir un reparto de las ganancias, de los beneficios o de los bienes de las fundaciones entre sus integrantes. La ausencia de ánimo de lucro no supone que las fundaciones no puedan obtener ingresos o beneficios por sus actividades, y esta posibilidad es compatible con el elemento de ausencia de fin de lucro de las mismas, lo que se traduce en que tales ingresos o beneficios deben revertir en la propia entidad o destinarse a la atención del objeto fundacional en el cumplimiento de los fines de interés general definidos por el fundador. Pero el mismo autor recuerda que el que la entidad sea constituida sin fin de lucro es una característica que tradicionalmente ha acompañado la regulación de las fundaciones: el desprendimiento altruista de una parte del patrimonio del fundador es el que en gran medida otorga la fuerza a su voluntad.

Verdera ${ }^{12}$ pone de manifiesto que no resulta fácil establecer qué debe entenderse por falta de ánimo de lucro. La Ley 49/2002, de 23 de diciembre, de Régimen Fiscal de las Entidades sin Fines Lucrativos y de los Incentivos Fiscales al Mecenazgo, no ofrece una definición de las entidades sin fines lucrativos, sino una enumeración de las mismas; por ello, resulta más adecuado tener en cuenta su art. 3 , que precisa los requisitos para que estas entidades puedan ser consideradas como no lucrativas, donde claramente se establece (en paralelo con el art. 3.3 de la Ley de Fundaciones) la prohibición de distribución de beneficios (como destinatarios principales o en condiciones especiales) para los patronos o los fundadores, o sus allegados. Por lo demás considera, como el anterior autor, que sólo hay ánimo de lucro cuando está previsto que una entidad realice un saldo activo entre costes e ingresos (lucro objetivo) que se halle destinado a ser distribuido entre sus integrantes (lucro subjetivo). García-Andrade ${ }^{13}$ se refiere igualmente a los requisitos exigidos por la Ley 49/2002, de 23 de diciembre, para que las entidades puedan ser consideradas entidades sin fines lucrativos.

En suma, cabe concebir que este elemento - la posibilidad de existencia de beneficios sin que ello suponga ánimo de lucro- se cualifica desde una doble perspectiva, cual es, por un lado, que las ganancias obtenidas por la fundación no se reparten entre sus integrantes, a diferencia de las

nes de las fundaciones al margen de la atención a los beneficiarios. Sentada la validez del beneficio en el seno de las fundaciones y la interdicción del fin de lucro en su constitución, las dos reglas son perfectamente conciliables, pues la fundación podrá obtener beneficios por sus actividades; ahora bien, éstos deberán revertir en la propia entidad o destinarse a la atención del objeto fundacional, pues lo que la Ley prohíbe es que las fundaciones sean constituidas con el ánimo de obtener beneficios».

${ }^{12}$ R. Verdera SERVER, op. cit., p. 97.

${ }^{13}$ J. García-ANDRADE GÓmEZ, op. cit., pp. 133 y 134. 
sociedades mercantiles o asociaciones que no sean de interés general, que lo hacen entre sus socios o asociados, y por otro, que, como quiera que la fundación actúa en áreas calificadas de interés general, el destino de tales beneficios a sus fines propios redunda - debiera redundar- en esa ausencia de ánimo de lucro, que se traduce en un ánimo de potenciar los intereses generales a que se orienta.

\section{Afección duradera de su patrimonio a la consecución de fines de interés general}

La Sentencia de la Audiencia Nacional de fecha 13 de diciembre de 2005 (JUR 2006 273363) pone de relieve que la dotación económica tiende a garantizar la viabilidad y seriedad de la utilización de esta forma jurídica de organización, caracterizada por la afectación, de forma duradera y estable, de un patrimonio a la realización de uno o varios fines de interés general. De modo que la existencia de un patrimonio inicial suficiente para cumplir el fin que se persigue se constituye como un elemento constitutivo del negocio jurídico fundacional. En el sentido de reputar esencial a las fundaciones la afección de su patrimonio por voluntad de sus creadores a la realización de fines de interés general se pronuncia también la Sentencia de la Sala de lo Contencioso-Administrativo del Tribunal Supremo de fecha 27 de abril de 2005 (Ar. 4557).

La doctrina ${ }^{14}$ destaca que el patrimonio es el elemento más característico de las fundaciones, que nacen cuando alguien (el fundador) decide aportar unos determinados bienes que el fundador vincula al cumplimiento de los fines de carácter general definidos por el mismo de manera duradera. Ello no quiere decir que no puedan constituirse fundaciones temporales, pero esta posibilidad se admite en la medida en que el plazo señalado

14 M. a L. Ortiz VAamonde, op. cit., pp. 23 y 24, pone de manifiesto que: «El patrimonio es el elemento más característico. Para que nazca una fundación es necesario que alguien decida libremente desprenderse de bienes propios. Sin patrimonio no hay fundación; [...] Los bienes de los que se desprende el fundador quedan vinculados a los fines de interés general de forma duradera; las fundaciones tienen una vocación de permanencia. Esto no significa que no puedan crearse fundaciones temporales, siempre que el plazo señalado no sea claramente insuficiente para cumplir su finalidad». J. GARcíA-ANDRADE GómEZ, op. cit., p. 41, corrobora que: «Una vez constituida la fundación, su patrimonio queda permanentemente afectado al cumplimiento de unos fines de interés general, cualesquiera que sean los avatares de la fundación en que se insertan esos bienes y derechos. Si la fundación se extinguiese, la vinculación del patrimonio a los fines de que se trate permanecería, ya sea al destinarlo a otra fundación o bajo cualquier otra forma jurídica». 
permita cumplir de manera suficiente su finalidad. La Exposición de Motivos de la Ley de Fundaciones destaca la importancia de los fines de interés general al expresar lo siguiente:

«la Ley pretende, a lo largo de su articulado, dinamizar y potenciar el fenómeno fundacional como cauce a través del cual la sociedad civil coadyuva con los poderes públicos en la consecución de interés general.

El Parlamento Europeo, en su Resolución sobre las fundaciones en Europa, señala en este sentido que "merecen apoyo especial las fundaciones que participen en la creación y desarrollo de respuestas e iniciativas adaptadas a las necesidades sociológicas de la sociedad contemporánea. Particularmente, las que luchan por la defensa de la democracia, el fomento de la solidaridad, el bienestar de los ciudadanos, la profundización de los derechos humanos, la defensa del medioambiente, la financiación de la cultura, las ciencias y las prácticas médicas y la investigación".

También nuestro Tribunal Constitucional (STC 18/1984, de 7 de febrero, entre otras) ha apuntado que una de las notas características del Estado social de Derecho es que los intereses generales se definen a través de una interacción entre el Estado y los agentes sociales, y que esta interpenetración entre lo público y lo privado trasciende también el campo de lo organizativo, en donde, como es fácil entender, las fundaciones desempeñan un papel de primera magnitud».

La importancia del elemento de los fines de interés general se ha recalcado por algunos autores ${ }^{15}$, pues es a su consecución a lo que se ha de afectar de manera duradera el patrimonio de la fundación; fines que pueden estar relacionados, como resulta de la Exposición de Motivos de la Ley de Fundaciones, con la ciencia, la educación, el deporte, la beneficencia, el arte, la economía, etc., siempre que sean relevantes para la sociedad.

Aunque se rechaza que el interés general del fin sea coincidente con el carácter genérico del colectivo de beneficiarios ${ }^{16}$, se destaca que las fundaciones benefician a grupos genéricos de personas, aunque su núme-

${ }^{15}$ M. a L. Ortiz VaAmonde, op. cit., pp. 23 y 24, escribe que: «El fin es otro elemento básico. Puede estar relacionado con la ciencia, la educación, el deporte, la beneficencia, el arte, la economía, etc., pero ha de ser relevante para la sociedad. Las fundaciones benefician a grupos genéricos de personas, nunca a sujetos previamente designados con exclusión de todos los demás. Y desde luego, no existen para el particular interés del fundador, que no crea la fundación pensando en su propio provecho».

16 R. VERDERA SERVER, op. cit., p. 102, expresa que: «Debe rechazarse, por último, que el interés general del fin sea coincidente con el carácter genérico del colectivo de beneficiarios, por cuanto caben colectivos beneficiados de escasa comprensión numérica. Nos hallamos ante un fin de interés general no en función del número del colectivo, sino de la considera- 
ro sea escaso, no a sujetos determinados, y se excluye que se constituyan para el interés particular del fundador, que no las puede crear en su propio beneficio.

Una vez explicados someramente los elementos de las fundaciones que se desprenden de su concepto legal se puede terminar este epígrafe destacando que la antedicha Sentencia de la Sala de lo Contencioso-Administrativo del Tribunal Supremo de fecha 27 de abril de 2005 (Ar. 4557) pone de relieve que las fundaciones, al integrase en el tipo de las personas jurídicas, se encuentran sometidas a un régimen análogo al resto de las entidades que integran aquéllas en cuanto a la posibilidad de que, prescindiendo de su forma externa, se proceda a levantar el velo de la personalidad jurídica fundacional para descubrir el verdadero sujeto real que la conforma a fin de evitar fraudes y abusos en el uso de la citada forma jurídica.

\section{RÉGIMEN JURÍDICO DE LAS FUNDACIONES}

Para que las fundaciones se puedan extinguir por imposibilidad de realización del fin fundacional es necesario que esta causa de extinción esté prevista en los instrumentos que rigen la vida jurídica de las fundaciones, y por tal motivo se hace necesario determinar cuáles son éstos.

El art. 2.2 de la Ley de Fundaciones, precepto de carácter básico, se refiere al régimen jurídico de las fundaciones al establecer que «las fundaciones se rigen por la voluntad del fundador, por sus Estatutos y, en todo caso, por la Ley».

\section{La voluntad del fundador}

Considera García-Andrade ${ }^{17}$ que la Ley no se refiere, al incorporar la voluntad del fundador a este precepto, a la voluntad del mismo expresada en los Estatutos, pues menciona a éstos específicamente en segundo lugar, y entiende que tampoco parece referirse a la voluntad manifestada en el acto de constitución de la fundación, la escritura o negocio fundacional,

ción social de que la atención a ese colectivo, aun escaso, es un fin socialmente amparable y promocionable».

${ }^{17}$ J. García-Andrade Gómez, op. cit., pp. 44 y ss. 
sino que más bien alude a «una voluntad a la que se pueda acudir durante la vida de la fundación, que sirva de referencia para el gobierno y destino de la entidad», lo que es coherente con la naturaleza de la institución en su conjunto, pues «nada impide que el fundador que esté presente en la vida de la institución pueda completar o aclarar su voluntad inicial», lo que parece ser el sentido que debe darse a la alusión del art. 2.2 de la Ley a la voluntad del fundador.

Ahora bien, en cuanto al alcance que tiene tal alusión no se puede dejar de manifestar que la autonomía de la voluntad ha cedido importancia a favor de la Ley, que se considera que es imperativa en muchos preceptos y que está inspirada por el principio de la prevalencia del interés general sobre la voluntad del fundador en caso de conflicto.

\section{Los Estatutos}

El mismo autor citado en el punto precedente ${ }^{18}$ pone de manifiesto que la pérdida de fuerza de la voluntad del fundador en la vigente Ley de Fundaciones se evidencia en el grado de respeto a los Estatutos de la fundación otorgados por el fundador, si bien es cierto que la Ley reserva cierta influencia del fundador en cuanto a la modificación de Estatutos, que el patronato podrá acordar siempre que resulte conveniente en interés de la misma, salvo que el fundador lo haya prohibido (art. 29.1), debiendo hacerlo cuando las circunstancias que presidieron la constitución de la fundación hayan variado de manera que ésta no pueda actuar satisfactoriamente con arreglo a los estatutos, salvo que para este supuesto el fundador haya previsto la extinción de la fundación (art. 29.2) y puede incluso llegar a asumir esa iniciativa el protectorado, que requerirá al patronato que no dé cumplimiento a lo previsto en el apartado anterior, para que así lo haga, solicitando en caso contrario de la autoridad judicial que resuelva sobre la procedencia de la modificación de los Estatutos requerida (art. 29.3). Influencia que también se refleja de cara a posibles fusiones, que el fundador puede prohibir (art. 31, puntos 1 y 4 ).

\footnotetext{
${ }^{18}$ Ibid., p. 49.
} 


\section{La Ley}

Determinados autores destacan que la Ley es imperativa en la mayor parte de sus preceptos, si bien matizan que «no puede afirmarse que el art. 2.2 de la Ley de Fundaciones consagra el carácter imperativo de cualquier disposición que resulte aplicable a las fundaciones», sino que «es preciso valorar el sentido de cada precepto para determinar en su caso si tiene o no carácter imperativo» ${ }^{19}$.

La prevalencia de la Ley se recoge su art. 11.2, según el cual «toda disposición de los Estatutos de la fundación o manifestación de la voluntad del fundador que sea contraria a la Ley se tendrá por no puesta, salvo que afecte a la validez constitutiva de aquélla». Se matiza por Verdera ${ }^{20}$ que ello se entiende así cuando se contradiga una previsión legal que tenga carácter imperativo.

La Ley de Fundaciones tiene por objeto, según su art. 1, desarrollar el derecho de fundación reconocido en el art. 34 de la Constitución y establecer las normas de régimen jurídico de las fundaciones que corresponde dictar al Estado, así como regular las fundaciones de competencia estatal.

En efecto, como reconoce la Sentencia del Tribunal Constitucional 341/2005, de 21 de diciembre, el reconocimiento por el precepto constitucional citado del «derecho de fundación para fines de interés general con arreglo a la ley», incluye una llamada al desarrollo legislativo, que ha de realizarse en los términos fijados en el art. 53.1 del mismo texto constitucional, y en el que al Estado compete ex art. 149.1.1 CE regular las condiciones básicas que garanticen la igualdad de todos los españoles en su ejercicio. Por otra parte, otros títulos competenciales del Estado —en los términos en que los consagra la Constitución - le habilitan igualmente para disciplinar el régimen jurídico de las fundaciones en los aspectos civiles y procesales (art. 149.1, núms. 8 y 6, CE), así como a estimular la participación de la iniciativa privada en la realización de actividades de interés general mediante medidas fiscales que le corresponde establecer de conformidad con el art. 149.1.14 CE.

La disposición final primera de la Ley de Fundaciones indica los artículos de la misma que son de general aplicación al amparo del art. 149.1.1. ${ }^{a}$ CE (apartado 1), al amparo de lo previsto en el art. 149.1.1. ${ }^{a}$ y 8. ${ }^{a} \mathrm{CE}$

${ }^{19}$ J. García-Andrade Gómez, op. cit., pp. 49 y 50; R. Verdera Server, op. cit., p. 108, y T. GonZÁlez Cueto, op. cit., pp. 53 y 54.

${ }^{20}$ R. Verdera Server, op. cit., p. 108. 
(apartado 2) y al amparo del art. 149.1.6. (apartado 3), y se prevé que los restantes preceptos de la Ley serán de aplicación a las fundaciones de competencia estatal.

La competencia exclusiva de las Comunidades Autónomas sobre las fundaciones que desarrollen principalmente sus funciones en su territorio ha sido asumida por la mayor parte de ellas y se ha incorporado al articulado de los distintos Estatutos de Autonomía. Algunas de ellas han dictado las Leyes de Fundaciones correspondientes a su ámbito territorial, textos en los que se ha respetado la Ley estatal en su vertiente de aplicación general ${ }^{21}$.

Dada la vocación generalista de este trabajo, sus referencias lo serán principalmente a la regulación que de la extinción de las fundaciones por imposibilidad de realización del fin fundacional se contiene en la Ley 50/2002, de 26 de diciembre, de Fundaciones, desarrollada por el Reglamento de Fundaciones de Competencia Estatal aprobado por el Real Decreto 1337/2005, de 11 de noviembre, y con ánimo no exhaustivo e integrador, a las leyes autonómicas.

\section{EXTINCIÓN DE LAS FUNDACIONES. CLASIFICACION DE LAS CAUSAS}

Las causas de extinción de las fundaciones se recogen en el art. 31 de la Ley de Fundaciones y admiten distintas clasificaciones.

\section{Clasificación realizada por nuestros Tribunales de Justicia}

La Sentencia del Juzgado de Primera Instancia núm. 17 de Valencia, de fecha 19 de enero de 2002 (JUR 2002\47677), contiene una clasifica-

${ }^{21}$ En efecto, se pueden citar las siguientes: la Ley 10/2005, de 31 de mayo, de Fundaciones de Andalucía; la Ley 2/1998, de 6 de abril, de Fundaciones de Canarias, a la que se añadió un Capítulo VI por la disposición adicional sexta de la Ley 11/2006, de 11 de diciembre; la Ley 13/2002, de 15 de junio, de Fundaciones de Castilla y León; la Ley 4/2008, de 24 de abril, por la que se da redacción al Libro Tercero del Código Civil de Cataluña relativo a las personas jurídicas; la Ley 8/1998, de 9 de diciembre, de Fundaciones de la Comunidad Valenciana, modificada por la Ley 9/2008, de 3 de julio; la Ley 12/2006, de 1 de diciembre, de Fundaciones de Galicia; la Ley 1/1998, de 2 de marzo, de Fundaciones de Madrid, modificada por la Ley 2/2004, de 31 de mayo; la Ley 12/1994, de 17 de junio, de Fundaciones del País Vasco, modificada por la Ley 7/2007, de 22 de junio, y la Ley 1/2007, de 12 de febrero, de Fundaciones de La Rioja. 
ción de las causas de extinción de las fundaciones contempladas en el art. 25 de la Ley valenciana de Fundaciones, que se remite a los arts. 29 y 30 de la Ley estatal de Fundaciones de 1994 en cuanto al régimen de los supuestos de extinción. En efecto, la indicada sentencia entiende que se pueden distinguir tres supuestos:

a) Extinción de pleno derecho. Se produce cuando «expire el plazo por el que fue constituida» la fundación, y ello por cuanto nada impide la fijación de un término de duración para la fundación y la llegada del mismo, salvo que previamente se haya procedido a una modificación estatutaria. Comporta la extinción ipso iure de la fundación y la apertura de su proceso de liquidación.

b) Extinción por acuerdo del patronato. Tal supuesto conforma el requisito para la extinción en tres supuestos, a saber:

- La realización íntegra del fin fundacional.

- La imposibilidad de realización del fin fundacional.

- La concurrencia de cualquier otra causa prevista en el acto constitutivo o en los estatutos.

c) Extinción de la fundación por resolución judicial motivada. Tal supuesto procede cuando concurra cualquier otra causa establecida en las leyes, así como en todos los casos en que la extinción de la fundación requiere el acuerdo del patronato y éste no se produce o no es ratificado por el protectorado.

\section{Clasificación defendida por la doctrina ${ }^{22}$}

Se distinguen las siguientes causas de extinción:

22 M. ${ }^{a}$ L. Ortiz VAamonde, op. cit., pp. 135 y 136, escribe que: «A veces la extinción es inevitable, quizá porque el propio fundador indicó los motivos de extinción (causas voluntarias), quizá porque las leyes prevén para ese supuesto su desaparición (causas forzosas o legales)». A continuación indica las causas que considera voluntarias y las causas que considera forzosas o legales, que son las que se contienen en este estudio. T. GonzÁlez Cueto, op. cit., p. 246, mantiene que: «La doctrina viene unánimemente distinguiendo entre causas de extinción voluntarias y legales. Las primeras serían las recogidas en las letras a) —expiración del plazo por el que la fundación fue constituida-y e) - cualquier otra prevista en el acto constitutivo o en los Estatutos-. Las causas establecidas por la Ley serían, en consecuencia, las referidas en las letras b) —íntegra realización del fin fundacional_, $c$ ) —imposibilidad de realización del citado fin_- d) —fusión_y f) —cualquier otra establecida en las leyes—. Seguidamente las explica. J. Caffarena Laporta en el libro de S. Muñoz Macha- 
a) Las causas voluntarias que el fundador pudiera haber previsto como causas de extinción, que si son válidas operarán cuando llegue el momento, como son:

- La llegada del plazo para el que fue constituida la fundación, pues al tratar el concepto de la fundación ya se puso de manifiesto que se admite la posibilidad de las fundaciones temporales cuando su periodo de existencia permita el cumplimiento de sus fines de interés general, lo que se entiende compatible con la exigencia de que sean duraderas. Esta causa voluntaria supone la extinción automática de la fundación sin necesidad de acuerdo ni declaración de ningún tipo, lo que dará lugar a la liquidación.

- La previsión de una condición resolutoria, cuyo cumplimiento pone fin a la fundación, siempre que sea válida. Ortiz ${ }^{23}$ considera que no sería válida la cláusula que hiciera depender la continuidad de la fundación de la voluntad del fundador o de terceras personas, si bien algún autor ${ }^{24}$ no considera seguro que entre las causas voluntarias quepa la condición resolutoria.

- Cualquier otra causa prevista en el acto constitutivo o en los estatutos que requiera acuerdo del patronato ratificado por el protectorado o, en su defecto, resolución judicial motivada a instancia del patronato o del protectorado.

b) Las causas forzosas o legales contempladas por las leyes, como son:

- La realización del fin fundacional, que la doctrina ${ }^{25}$ incluye en este apartado para el caso infrecuente de que el fundador hubiera previsto uno muy concreto que pudiera realizarse totalmente.

- La imposibilidad de realización del fin fundacional, cuando no se pueda mantener la existencia de la fundación bien mediante una modificación de los Estatutos o bien mediante la fusión de la fundación con otras fundaciones.

Do, M. Cruz Amorós y R. de Lorenzo García (dirs.), Comentarios a las Leyes de Fundaciones y de Mecenazgo, Madrid, Fundación ONCE, 2005, pp. 465 y ss., en que recoge la misma clasificación y explica las distintas causas.

${ }^{23}$ M. ${ }^{a}$ L. ORTIZ VAAMONDE, op. cit., pp. 135 y 136.

${ }^{24}$ C. Vattier FuenZalida, «Observaciones sobre la constitución, la modificación y la extinción de las fundaciones», en Diario La Ley, Sección Doctrina, 1998, ref. D-119, t. 3 , La Ley, p. 8.

${ }^{25}$ M. ${ }^{a}$ L. Ortiz VaAmonde, op. cit., pp. 135 y 136. 
- La fusión en que se une una fundación a otra fundación para que continúen su actividad, supuesto en que se extingue la fundación que se une a otra, siendo esta última la que subsiste.

- Cualquier otra causa prevista en las leyes que requiera resolución judicial motivada a instancia del patronato o del protectorado.

\section{EXTINCIÓN DE LAS FUNDACIONES POR IMPOSIBILIDAD DE REALIZACIÓN DEL FIN FUNDACIONAL}

\section{Casos en que concurre la imposibilidad de realización del fin fundacional}

$\mathrm{El}$ art. 31.c) de la Ley de Fundaciones dispone que la fundación se extinguirá cuando sea imposible la realización del fin fundacional, sin perjuicio de lo dispuesto en los arts. 29 y 30 de la presente Ley. Los arts. 29 y 30 de la Ley se refieren, como se ha visto, a la modificación de los Estatutos y a la fusión de fundaciones. En los mismos términos se regula esta causa de extinción en los correspondientes artículos de las leyes autonómicas ${ }^{26}$.

Conviene a estos efectos clarificar qué debe entenderse por «imposibilidad», a los efectos de aplicar esta concreta causa de extinción.

La doctrina ${ }^{27}$, en una primera aproximación, considera que la imposibilidad que se contempla en la normativa aplicable en cada caso puede ser material, es decir, la que se produce por razones fácticas o físicas («las circunstancias que presidieron la creación de una fundación pueden cambiar con el paso del tiempo de una manera muy significativa, de tal forma que hagan inviable la consecución del fin o fines fundacionales»), o jurídica, esto es, la que resulta por razones de tipo normativo o jurídico («las

${ }^{26}$ La Ley 10/2005, de 31 de mayo, de Fundaciones de Andalucía, la contempla en el art. 42.1.c); la Ley 2/1998, de 6 de abril, de Fundaciones de Canarias, la regula en su art. 31.c); la Ley 13/2002, de 15 de julio, de Fundaciones de Castilla y León, se remite a la legislación estatal; la Ley 4/2008, de 24 de abril, por la que se añade el Libro Tercero del Código Civil de Cataluña, la denomina causa de disolución en el art. 2.254.c); la Ley 8/1998, de 9 de diciembre, de Fundaciones de la Comunidad Valenciana, modificada por la Ley $9 / 2008$, de 3 de julio, se remite a los arts. 31 y 32 de la Ley 50/2002, de 26 de diciembre, de Fundaciones; la Ley 12/2006, de 1 de diciembre, de Fundaciones de Galicia, la recoge en su art. 44.1.c), y la Ley 1/2007, de 12 de febrero, de Fundaciones de La Rioja, la contempla en su art. 38.1.c).

${ }^{27}$ J. CAffarena Laporta, op. cit., pp. 469 y ss., y T. GonzÁlez Cueto, op. cit., pp. 245 y ss. 
modificaciones del ordenamiento jurídico convierten en muchas ocasiones algo que era lícito en ilícito o viceversa»). Una segunda aproximación permite distinguir que la imposibilidad puede afectar al fin mismo, que ya no existe o es ahora contrario a Derecho, o a los medios para alcanzar tal fin, porque resulten inidóneos para ello, hayan desaparecido o se reduzcan de forma sustancial.

Y de igual modo, la imposibilidad puede producirse por un cambio de las circunstancias externas a la fundación o de las internas de la misma. Ahora bien, en cualquier caso la imposibilidad, para dar lugar a la extinción, ha de ser total y permanente, que no admita una modificación de sus elementos que permita conservar su existencia, pero estos términos no deben entenderse de modo estricto.

La imposibilidad material de realización del fin fundacional se considera que concurre en una serie de supuestos a los que se refieren nuestros Tribunales de Justicia, que pueden producir la imposibilidad cada uno por separado o bien pueden concurrir todos o varios de ellos a los efectos indicados. Tales supuestos, que cabe extraer de la casuística judicial, son: (i) que los miembros del patronato no hayan aceptado el cargo o que, habiéndolo aceptado, no se reúnan periódicamente, dándose en muchos casos la circunstancia de que no se les puede localizar; (ii) que la fundación no desarrolle actividad alguna durante algún tiempo; (iii) que la fundación no disponga de patrimonio suficiente para desarrollar su actividad; (iv) que la fundación no cuente con los recursos necesarios a tal fin. En este sentido, Martí considera ${ }^{28}$ que entre estos supuestos debe comprenderse también la circunstancia, frecuente, de haberse agotado el patrimonio de la fundación, o quedar tan disminuido que haga imposible el desarrollo normal de las actividades programadas.

Así, la Sentencia del Juzgado de Primera Instancia núm. 17 de Valencia, de fecha 19 de enero de 2002, antes citada, se refiere al supuesto de una fundación, la denominada Fundación Oloriz, en que los llamados a ostentar el cargo de patronos en modo alguno habían venido a aceptar el cargo, en que no se había acreditado actividad alguna de la fundación en los últimos años y en que hasta se alegaba el desconocimiento del patrimonio actual de la fundación. En este caso se declaró que concurría el supuesto de extinción, cuya declaración resultaba obligada, pues se concluyó la evidencia de la imposibilidad de realización de los fines fundacionales rela-

${ }^{28}$ R. Martí Lacalle, en J. Olavarría Iglesia (coord.), Comentarios a la Ley de Fundaciones, Valencia, Tirant lo Blanch, 2008, pp. 818 y ss. 
tivos a la mejora y enriquecimiento de la biblioteca de la Facultad de Derecho (de la Universitat de Valencia-EG), así como la concesión de premios a los alumnos sobresalientes que se estimen acreedores de ellos. Por todo ello, se consideró procedente dictar resolución por la que se decrete la extinción de la fundación, la inscripción de este acuerdo en el Registro de Fundaciones (conforme al art. 25.2 de la Ley valenciana de Fundaciones) y la ulterior y consiguiente liquidación ex art. 26, lo que, según acordó el Juzgado, se debía llevar a efecto en la fase de ejecución de la propia sentencia extintiva, cuestión a la que haremos ulterior referencia.

La Sentencia de la Audiencia Provincial de Toledo de fecha 17 de junio de 2005 (JUR 2005\161647) se refiere a otro supuesto, el de inexistencia de medios económicos para realizar la restauración y asegurar el mantenimiento del edificio fundacional, ya que las obras de restauración necesarias para su rehabilitación resultaban superiores a los 90.000 euros y la fundación carecía de bienes para acometer no sólo la restauración, sino el mantenimiento mismo del edificio. En este caso estimó la demanda al entenderse debidamente acreditada la causa de extinción aducida por la parte actora, que era la imposibilidad de realización del fin fundacional con base en lo dispuesto en el art. 31.1.c) de la Ley de Fundaciones del año 2002.

La Sentencia de la Audiencia Provincial de Álava de fecha 14 de julio de 2008 (AC 2008\2014) examinó el caso de la insuficiencia patrimonial sobrevenida y puesta de manifiesto en los autos, que también se entiende que da lugar a la imposibilidad material de realización del fin fundacional.

Hasta el Tribunal Supremo, en la Sentencia de 21 de abril de 1999 (Ar. 4178), se pronunció sobre la aplicación de esta causa de extinción en un caso en que el patrimonio fundacional no permitía el cumplimiento adecuado de los fines fundacionales, si bien precisando que lo que se perseguía en sede jurisdiccional era revisar si fue correcta y adecuada a Derecho la denegación de que la fundación se extinguiera a la vista de la valoración de la entidad y de los frutos o rendimientos que pudieran obtenerse del patrimonio fundacional. Examinados los autos, la Sala comparte el juicio de que, según las reglas de la sana crítica, ha de aceptarse el informe pericial que valora los terrenos y el edificio que constituyen el patrimonio fundacional en una cantidad ligeramente superior a 267 millones de pesetas. A partir de este dato, y considerando que consta en autos y no ha sido discutida la existencia de una deuda de la fundación con la Compañía de Jesús que asciende a más de 230 millones de pesetas, se concluye que desde luego la situación económica de la fundación, aun reconvirtiendo o administrando de otro modo el patrimonio fundacional con las auto- 
rizaciones administrativas oportunas, no permite el cumplimiento adecuado de los fines fundacionales. Por tanto, la Sala se pronuncia en el sentido de que la valoración efectuada por la Administración que ejercía el protectorado fue errónea y no se encontraba adecuada a la realidad, procediendo, en consecuencia, la aplicación de los Estatutos fundacionales y del art. 39 del Código Civil en el sentido de que los bienes no eran suficientes para cumplir los fines y, por tanto, tenía fundamento suficiente el acuerdo de extinción adoptado por la Junta de Patronos que debió ser confirmado en ejercicio de sus potestades por la Administración. En consecuencia, el Tribunal Supremo estima el recurso contencioso-administrativo interpuesto ante el Tribunal a quo contra la negativa a adoptar el acuerdo administrativo de extinción, producida en virtud del efecto negativo del silencio guardado por la Administración.

Una vez examinado lo que se entiende por imposibilidad de realización del fin fundacional, la doctrina ${ }^{29}$ analiza también el alcance del inciso final del apartado c) del art. 31: «Sin perjuicio de lo dispuesto en los arts. 29 y 30 de la presente Ley», que se refieren a la modificación de los Estatutos y la fusión de fundaciones.

En cuanto al primero de estos artículos, que trata la modificación de los Estatutos, el apartado 2 del mismo prevé que cuando las circunstancias que presidieron la constitución de la fundación hayan variado de manera que ésta no pueda actuar satisfactoriamente con arreglo a sus Estatutos, el patronato deberá acordar la modificación de los mismos, salvo que para este supuesto el fundador haya previsto la extinción de la fundación.

La doctrina antes referida entiende que «la finalidad de interés general que posee la fundación justifica que el efecto extintivo sólo debe producirse cuando no sea posible una modificación de la fundación para que el fin se pueda realizar o incluso se realice otro análogo. En consecuencia, a falta de previsión expresa, la extinción de la fundación por imposibilidad sobrevenida del cumplimiento del fin fundacional tiene carácter subsidiario respecto de la modificación de estatutos».

En cuanto al art. 30, que trata la fusión de fundaciones, el apartado 1 del mismo establece que las fundaciones, siempre que no lo haya prohibido el fundador, podrán fusionarse previo acuerdo de los respectivos patronatos, que se comunicará al protectorado. El apartado 4 del mismo artículo dispone que: «Cuando una fundación resulte incapaz de alcanzar sus fines, el protectorado podrá requerirla para que se fusione con otra de análogos

\footnotetext{
${ }^{29}$ Seguimos en este punto a R. MarTí LaCALle, op. cit., pp. 819 y ss.
} 
fines que haya manifestado ante el protectorado su voluntad favorable a dicha fusión, siempre que el fundador no lo hubiera prohibido».

La doctrina que venimos siguiendo pone de manifiesto que del precepto trascrito puede resultar que el alcance de la fusión es distinto al que posee la modificación de los estatutos respecto de la extinción. En efecto, la fusión se contempla como una alternativa a la extinción, pues su adopción se concibe como una facultad y no como una obligación, a diferencia del tenor del art. 29.2, en relación con la modificación de estatutos, y además la fusión conllevará la extinción de la fundación. No obstante, se estima que si la fusión va a permitir que se continúen adaptando los fines a las circunstancias sobrevenidas, se producirá el mismo efecto que en la modificación de estatutos.

El Tribunal Supremo, en su Sentencia de 4 de julio de 2005 (Ar. 6900), ha destacado la intervención del protectorado en estos casos, declarando que en estas hipótesis la Ley ha puesto en manos del protectorado algunas formas de intervención más incisivas, si bien siempre mirando a preservar los fines fundacionales y manteniéndolas en el plano de la legalidad. Así, es el patronato el que tiene la facultad de adoptar las decisiones correspondientes para la modificación de los estatutos, pero ha de contar con la autorización previa del protectorado, el cual puede, incluso, disponerla de oficio o a instancia de quien tenga interés legítimo cuando el patronato no cumpla el deber de hacerla en el caso de que la variación de las circunstancias impidan a la fundación actuar satisfactoriamente conforme a sus estatutos. Además, la Ley autoriza al protectorado a oponerse por razones de legalidad y mediante acuerdo motivado a la nueva redacción o modificación estatutarias que han de serle comunicadas. De igual modo, se reconoce al protectorado la facultad de oponerse a la fusión con otra fundación decidida por los respectivos patronatos, pero solamente por motivos de legalidad y mediante acuerdo motivado que deberá adoptarse en el plazo máximo de tres meses a contar desde que le fueren notificados los acuerdos de las fundaciones afectadas. Asimismo, puede el protectorado solicitar de la autoridad judicial la fusión de aquellas fundaciones que no puedan cumplir sus fines por sí mismas cuando éstos sean análogos y exista oposición de sus órganos de gobierno, no habiéndolo prohibido el fundador. Tal solicitud habrá de formularse ante el Juzgado de Primera Instancia del domicilio de la fundación, tramitándose conforme a lo dispuesto para los incidentes por la Ley de Enjuiciamiento Civil.

Como corolario de todo lo expuesto en este punto cabe colegir que la imposibilidad como causa extintiva se encuentra íntimamente ligada al 
dato objetivo de si la estructura fundacional, en abstracto, puede seguir atendiendo los fines de interés general para los que fue creada, de modo que si cabe su consecución sin llegar a desdibujarlos, la vocación de permanencia de la misma se impone, incluso aun cuando haya que servirse de mecanismos tales como la modificación estatutaria o la fusión. Si, por el contrario, no se pueden alcanzar o si se alteran bajo diversas fórmulas tales fines hasta el punto de hacerlos irreconocibles en su configuración primigenia, la única opción será la extinción.

\section{Requisitos necesarios para que opere esta causa de extinción}

En cuanto a los requisitos para que la extinción pueda producirse, a ellos se refiere la Sentencia de la Audiencia Provincial de Álava de fecha 14 de julio de 2008 (AC 2008\2014), que indica que, en el caso que contempla, en que concurre la causa de extinción de imposibilidad de realización del fin fundacional, la extinción de la fundación requiere acuerdo del patronato ratificado por el protectorado, y si no hubiese acuerdo del patronato, o éste no fuese ratificado por el protectorado, la extinción de la fundación requerirá resolución judicial motivada que podrá ser instada por el protectorado o por el patronato, que en consecuencia son los únicos facultados por la Ley para tal acción.

En efecto, los requisitos necesarios para que opere esta causa de extinción se contemplan en el art. 32.2 de la Ley de Fundaciones, que establece que, en el supuesto indicado, la extinción requerirá acuerdo del patronato ratificado por el protectorado. Si no hubiese acuerdo del patronato, o éste no fuese ratificado por el protectorado, la extinción de la fundación requerirá resolución judicial motivada, que podrá ser instada por el protectorado o por el patronato, según los casos. El apartado 4 del mismo art. 32 dispone que el acuerdo de extinción o, en su caso, la resolución judicial, se inscribirán en el correspondiente Registro de Fundaciones.

La doctrina ${ }^{30}$ se refiere en el mismo sentido a los requisitos que exige la Ley de Fundaciones explicando que en estos casos, por tanto, la causa de extinción no opera automáticamente, sino que la extinción requiere el

${ }^{30}$ J. CAFFARENA LAPORTA, op. cit., pp. 476 y ss.; T. GONZÁlez Cueto, op. cit., pp. 245 y ss.; R. Martí Lacalle, op. cit., pp. 827 y ss.; A. Nieto Alonso, en R. De Lorenzo, J. L. Piñar y T. SAnjurjo (dirs.), Tratado de Fundaciones, Navarra, Aranzadi, 2010, pp. 183 y ss., y R. BeRGÓs, G. BERgós y R. Gómez, Todo sobre las Fundaciones. Manual, legislación y formularios, Madrid, Difusión Jurídica, 2008. 
acuerdo del patronato ratificado por el protectorado. Se añade que «dicho acuerdo no se limita a declarar que se ha producido la causa de extinción, sino que implica la extinción de la fundación, si bien la eficacia extintiva del acuerdo se hace depender de su ratificación por el protectorado».

El art. 38.1 del Real Decreto 1337/2005, del Reglamento de Fundaciones de Competencia Estatal, desarrolla el art. 32.2 de la Ley de Fundaciones, disponiendo que cuando el patronato acuerde extinguir la fundación por haberse realizado íntegramente el fin fundacional, por resultar imposible su realización o por concurrir cualquier otra causa prevista en el acto constitutivo o en los estatutos, deberá solicitar la ratificación del protectorado, para lo que acompañará la siguiente documentación:

a) Certificación del acuerdo de extinción adoptado por el patronato, emitido por el secretario con el visto bueno del presidente.

b) Memoria justificativa de la causa de extinción específica de las previstas en el primer párrafo de este apartado. En el supuesto de que la causa de extinción sea la imposibilidad de realizar el fin fundacional, habrá que justificar, además, la improcedencia o la imposibilidad de modificar los estatutos o de llevar a cabo un proceso de fusión.

c) Las cuentas de la entidad a la fecha en que se adoptó el acuerdo de extinción.

d) El proyecto de distribución de los bienes y derechos resultantes de la liquidación.

El protectorado, una vez examinada la documentación aportada por el patronato, y en el plazo de tres meses, resolverá de forma motivada sobre la ratificación del acuerdo de extinción. A falta de resolución expresa debidamente notificada en el plazo citado, el acuerdo de extinción podrá entenderse ratificado. Si la resolución fuese denegatoria, el patronato podrá instar ante la autoridad judicial la declaración de extinción de la fundación.

El punto 2 del mismo artículo dispone que si el protectorado apreciara de oficio la concurrencia de alguno de los supuestos de extinción previstos en el apartado anterior, comunicará al patronato la necesidad de adoptar el acuerdo de extinción en el plazo que al efecto señale, que no podrá ser inferior a tres meses. Transcurrido dicho plazo sin que el patronato hubiera adoptado el acuerdo de extinción requerido, o ante su oposición expresa, el protectorado podrá solicitar de la autoridad judicial la declaración de extinción de la fundación. Y el punto 4 añade que el acuerdo de extinción, 
que deberá constar en escritura pública, o, en su caso, la resolución judicial, se inscribirán en el Registro de Fundaciones de Competencia Estatal.

Las leyes autonómicas ${ }^{31}$ vienen a establecer los mismos requisitos que la Ley estatal.

La Sentencia de la Sala de lo Contencioso-Administrativo del Tribunal Supremo de fecha 4 de julio de 2005 (Ar. 6900), que se refiere a la anterior Ley 30/1994, que contemplaba la misma causa de extinción, viene en suma a ratificar las pautas que ley y reglamento marcan.

De todo ello cabe extraer que esta causa no opera automáticamente, y que requiere de la intervención gradual de tres órganos: patronato, como primer y directo observador de la situación de imposibilidad que, de apreciarla fundadamente, deberá acordar la extinción; protectorado, que bien ratificará lo acordado por el primero, bien velará por el mantenimiento de la entidad en caso de apreciación errónea por el primero, o bien promoverá la extinción en ausencia - física o ejecutiva- del primero, y la autoridad judicial, que velará en caso de conflicto entre los anteriores por el cumplimiento de los fines fundacionales.

\section{Intervención del protectorado}

Explica Ortiz ${ }^{32}$ que las fundaciones tienen una faceta privada, en la medida en que nacen por voluntad de una persona, física o jurídica, que libremente decide desprenderse de bienes propios a favor de la entidad que va a constituir, pero que junto a ella existe una faceta pública, ya que las fundaciones persiguen fines de interés general, lo que justifica la injerencia de los poderes públicos, que en beneficio de la entidad destinataria de esos bienes deberá supervisar el correcto funcionamiento de la fundación. El protectorado es el principal órgano administrativo que asume esta importante función de tutela sobre las fundaciones.

${ }^{31}$ La Ley 10/2005, de 31 de mayo, de Fundaciones de Andalucía, así lo recoge en su art. 42; la Ley 2/1998, de 6 de abril, de Fundaciones de Canarias, lo establece en los mismos términos en el art. 31; la Ley 13/2002, de 15 de julio, de Fundaciones de Castilla y León, se remite, en su art. 30, a los términos previstos en la normativa estatal que resulten de aplicación; la Ley 8/1998, de 9 de diciembre, de Fundaciones de la Comunidad Valenciana, se remite también, en su art. 25, a lo dispuesto en la normativa estatal; la Ley 12/2006, de 1 de diciembre, de Fundaciones de Galicia, contiene los mismos requisitos en su art. 44, y la Ley 1/2007, de 12 de febrero, de Fundaciones de La Rioja, se remite a la legislación estatal en su art. 39.

${ }^{32}$ M. ${ }^{a}$ L. Ortiz VaAmonde, op. cit., pp. 139 y ss. 
En efecto, de los elementos que se desprenden del planteamiento legal que son esenciales en el concepto de las fundaciones a que se refiere el apartado I de este estudio, el de los fines de interés públicos a cuya consecución debe afectarse de forma duradera el patrimonio de la fundación, es el elemento que justifica la intervención de la Administración a través del protectorado, como reconoce el Tribunal Constitucional en la Sentencia 341/2005, de 21 de diciembre (RTC 2005\341), que declara que «del rasgo básico que supone el que las fundaciones tengan un fin de interés general se deriva la exigencia de la intervención administrativa». Alude a la anterior Sentencia del mismo Tribunal Constitucional 164/1990, de 29 de octubre, en la que se decía que las competencias de los poderes públicos en la materia encuentran su razón de ser evidente «en la necesidad de proveer a la Administración de los instrumentos necesarios para asegurar que las fundaciones no se desvían de los fines de interés público que según el Código Civil (art. 35.1) le son propios»; función que, aun en el mismo orden de consideraciones, entiende la sentencia que hay que completar con la más genérica de evitar la existencia de fundaciones ilegales por sus fines o por los medios que utilicen (art. 34.2 CE, en relación con el art. 22.2 CE).

En este sentido, la Sentencia de la Audiencia Provincial de Valencia de fecha 6 de mayo de 1993 (AC 1993\930) ya había considerado con anterioridad que no parece contrario a la legislación civil que, en atención a los fines de intereses generales que se propugnan, tenga la Administración la «pertinente y oportuna participación en la gestión, vigilancia y cumplimiento de los fines fundacionales [...] ejerciendo el protectorado de la misma» [STS (Sala 1.a) de 10 de julio de 1985 (RJ 1985\4135)], pues esa intervención «no hay por qué contemplarla como dirigida a desvirtuar o contrariar la voluntad del fundador, sino, por el contrario, a asegurar la misma» [STS (Sala Contencioso-Administrativo) de 20 de diciembre de 1985 (RJ 1986\669)].

El Tribunal Supremo se pronuncia en el mismo sentido en la Sentencia de 4 de julio de 2005 (Ar. 6900) al indicar que las fundaciones son, ante todo, personas jurídicas de Derecho privado, surgidas de la autonomía de los particulares y ajenas a la organización pública. No obstante, la relevancia que la Constitución les asigna cuando reconoce en su art. 34 el derecho a la fundación para fines de interés general y las somete, además de a la regulación legal, a las previsiones de su art. 22.2 y 4, hace que, precisamente en atención a esos fines de interés general, el legislador haya previsto la intervención del protectorado, ejercido por la Administración General del Estado respecto de las fundaciones de competencia estatal, en diversos aspectos de las mismas. 
Por tanto, legal y doctrinalmente la fundación es una persona jurídica que, aun orientada a fines de interés general que justifican una cierta intervención administrativa, tiene su propia autonomía, lo que hace que el espíritu de la ley sea que la intervención del protectorado se oriente de cara al cumplimiento de la legalidad y a la consecución de esos fines, fuera de lo que sea estrictamente formal y reglado, que su intervención sea mínima, y que sólo puedan plantearse cuestiones como la modificación estatutaria, la fusión, la intervención y, en particular, la extinción, como una «última ratio» a adoptar por el protectorado.

Obvio es decirlo, la Constitución (arts. 34.2 y 22.4) exige para disolver una fundación resolución judicial, pues se trata no sólo de intervenir en el asociacionismo privado (ya se entienda éste desde una perspectiva estricta como desde la societaria o fundacional), sino también en el proceso de desaparición de una persona jurídica.

Igualmente, el espíritu de la norma es procurar el mantenimiento de la entidad para que se sigan alcanzando los fines de interés general para los que se creó, por lo que la extinción se contempla sólo como la última posibilidad, tras haberse agotado las previas que puedan utilizarse.

El protectorado, por tanto, de acuerdo con el art. 34.1 de la Ley de Fundaciones, y con una fórmula casi idéntica a la de la anterior Ley, es el órgano administrativo encargado de velar por el correcto ejercicio de fundación y por la legalidad de la constitución y funcionamiento de las fundaciones, y en el mismo sentido se define por las leyes autonómicas ${ }^{33}$.

33 La Ley 10/2005, de 31 de mayo, de Fundaciones de Andalucía, así lo define en su art. 44 referido al protectorado de fundaciones andaluzas; la Ley 2/1998, de 6 de abril, de Fundaciones de Canarias, define en su art. 34 el protectorado de fundaciones canarias como el órgano administrativo de asesoramiento, apoyo técnico y control de las fundaciones, que facilitará el recto ejercicio del derecho fundacional y asegurará la legalidad de su constitución y funcionamiento; la Ley 13/2002, de 15 de julio, de Fundaciones de Castilla y León, define en su art. 32 el protectorado como el órgano administrativo de asesoramiento, apoyo técnico y control de las fundaciones; la Ley 4/2008, de 24 de abril, modifica el Código Civil de Cataluña dando al art. 336.2 la redacción que define el protectorado como el órgano que debe velar por que se cumplan las finalidades fundacionales, las disposiciones legales y los estatutos de las fundaciones y por que se respete la voluntad fundacional; la Ley 8/1998, de 9 de diciembre, de Fundaciones de la Comunidad Valenciana, define en su art. 28 el protectorado como el órgano administrativo de la Generalitat que ejerce las funciones que le atribuye la legislación vigente respecto de las fundaciones inscritas en el Registro de Fundaciones de la Comunitat Valenciana, de acuerdo con lo que se establezca reglamentariamente; la Ley 12/2006, de 1 de diciembre, de Fundaciones de Galicia, define en su art. 47 el protectorado como el órgano administrativo de asesoramiento, apoyo técnico y control de las fundaciones que velará por el ejercicio correcto del derecho de fundación y por la legalidad de su constitución y funcionamiento; la Ley 1/1998, de 2 de marzo, de Fundaciones de Madrid, define el protectorado en su art. 28 como el órgano administra- 
La Sentencia del Tribunal Supremo de fecha 20 de diciembre de 2003, (Ar. 614 de 2004), referida al art. 32 de la anterior Ley 30/1994, afirma que este precepto atribuye ciertamente al protectorado funciones de control de los actos de constitución y funcionamiento (en el punto 1), pero lo hace desde el exclusivo parámetro de la «legalidad», y también le asigna [en el punto 2, apartados b) y c)] las funciones de «velar por el efectivo cumplimiento de los fines fundacionales de acuerdo con la voluntad del fundador» $\mathrm{y}$ «verificar si los recursos de la fundación han sido aplicados a los fines fundacionales».

Hay, pues, dos grupos de atribuciones referidos a finalidades distintas $\mathrm{y}$ a actos igualmente diferentes:

- Por un lado, está el control que corresponde al protectorado desde la premisa de la voluntad del fundador, pero que es expresamente referido al cumplimiento de los fines fundacionales que por dicho fundador hayan sido definidos, lo cual significa que este control consiste en verificar si los actos exteriores que realice la fundación como ente o persona jurídica, esto es, los de su tráfico jurídico externo, persiguen o no las metas de interés general que encarnan los fines fundacionales.

- Por otro lado, está la intervención atribuida al protectorado en relación con el funcionamiento interno de la fundación, circunscrita únicamente al control de su legalidad, sin mencionarse nada relativo a la vigilancia de si esos actos internos son o no conformes con la voluntad del fundador. Lo cual no quiere decir, como luego se pondrá de manifiesto, que no exista para los miembros del órgano de gobierno que pudieran resultar afectados la posibilidad de reaccionar frente a esos actos internos.

También otros preceptos de la Ley 30/1994 confirmaban lo anterior, demostrando con ello la idea primigenia de no establecer un control ilimitado del protectorado sobre el funcionamiento interno de la fundación en cualquier supuesto, sino únicamente una intervención extrema en aque-

tivo de asesoramiento, apoyo técnico y control de las fundaciones, que facilitará y promoverá el recto ejercicio del derecho de fundación y asegurará la legalidad de su constitución y funcionamiento; la Ley 12/1994, de 17 de junio, de Fundaciones del País Vasco, define el protectorado en su art. 36 como el órgano administrativo de asesoramiento, apoyo técnico y control de las fundaciones que facilitará y promoverá el recto ejercicio del derecho fundacional y asegurará la legalidad de su constitución y funcionamiento, y la Ley 1/2007, de 12 de febrero, de Fundaciones de La Rioja, define el protectorado en su art. 41 como el órgano administrativo de asesoramiento y apoyo técnico de las fundaciones que velará por el correcto ejercicio del derecho de fundación y por la legalidad de la constitución y funcionamiento de las fundaciones. 
llos casos excepcionales expresamente previstos como representativos de la imposibilidad de la normal continuidad de la fundación.

La nueva Ley 50/2002 continúa en la línea de la anterior, y en sus arts. 34 y 35 el protectorado aparece con unas funciones sustancialmente coincidentes con las que tenía en la Ley 30/1994, y en el art. 43.3 contiene una amplia relación de las pretensiones que corresponderán a la jurisdicción civil (al Juzgado de Primera Instancia del domicilio de la fundación), que están referidas a materias relacionadas en muchos casos con la constitución y el funcionamiento interno de la fundación.

La Exposición de Motivos de la Ley de Fundaciones destaca como uno de los objetivos de la misma «reducir la intervención de los poderes públicos en el funcionamiento de las fundaciones. Así, se ha sustituido en la mayor parte de los casos la exigencia de autorización previa de actos y negocios jurídicos por parte del protectorado por la simple comunicación al mismo del acto o negocio realizado, con objeto de que pueda impugnarlo ante la instancia judicial competente si lo considera contrario a Derecho y, eventualmente, ejercitar acciones legales contra los patronos responsables». Se destaca igualmente en ella que «el Capítulo VII reformula las funciones del protectorado, potenciando las de apoyo y asesoramiento a las fundaciones sobre las que ejerce su competencia, en especial a las que se encuentran en proceso de constitución».

La Sentencia del Tribunal Superior de Justicia de Madrid de fecha 26 de enero de 1998 (RJCA 1998\1064) se refirió a la intervención del protectorado en los términos regulados por la anterior Ley, destacando, de acuerdo con lo afirmado por otros Tribunales de Justicia, que por el carácter de institución destinada al cumplimiento de fines generales y públicos, en beneficio de colectividades indeterminadas de personas, la Administración Pública, como encargada de la tutela y gestión de los servicios públicos, interviene en la actividad de las fundaciones desde su nacimiento, y si bien es cierto que se ha discutido mucho sobre dicha intervención, existiendo gran polémica sobre tal cuestión, lo cierto es que el Tribunal Constitucional tiene declarado al respecto en su Sentencia 49/1988, de 22 marzo (RTC 1988\49), que «las leyes pueden prever un tipo de acción administrativa, el protectorado, para asegurar el cumplimiento de los fines de las fundaciones y la recta administración de los bienes que las forman, debiéndose mover su intervención dentro de los límites del art. 34 de la Constitución».

En definitiva, en nuestro sistema, la intervención de la Administración en la vida de las fundaciones - a través del protectorado- se concibe 
como legítima y como parte esencial del Derecho constitucional de fundación que, debe recordarse, presenta una marcada configuración legal y no se concibe como derecho fundamental, a diferencia del de asociación.

Ahora bien, en cuanto al contenido y alcance de esta intervención, la doctrina y jurisprudencia vienen señalando que esta intervención se ha de ejercitar dentro de unos límites precisos que respeten el marco de libertad y garantía que la Constitución impone, afirmándose que no se trata de «controlar» sin más el ejercicio del derecho de fundación, sino de «garantizar»su recto ejercicio.

El protectorado de las fundaciones de competencia estatal será ejercido por la Administración General del Estado en la forma que reglamentariamente se determine (art. 34.2 de la Ley de Fundaciones), mientras que el protectorado de las fundaciones autonómicas será ejercido por el órgano competente en cada caso en materia de fundaciones, en la forma que reglamentariamente se determine según las leyes autonómicas ${ }^{34}$.

De lo expuesto en el epígrafe referido a los requisitos necesarios para que opere esta causa de extinción por imposibilidad de realización del fin fundacional resulta que, en relación con dicha causa de extinción, el protectorado interviene para ratificar la decisión extintiva del patronato, se adopte ésta por iniciativa propia del patronato o a instancia del protectorado, en el caso en que éste apreciara de oficio la concurrencia de alguno de los supuestos de extinción previstos en el art. 38.1 del Real Decreto 1337/2005, de 11 de noviembre, entre los que se encuentra el que nos ocupa.

${ }^{34}$ La Ley 10/2005, de 31 de mayo, de Fundaciones de Andalucía, establece, en su art. 44.2, que será ejercido por la consejería competente en materia de fundaciones, en la forma que se determine reglamentariamente; la Ley 2/1998, de 6 de abril, de Fundaciones de Canarias, dispone, en su art. 35, que será ejercido por la Administración de la Comunidad Autónoma de Canarias, en la forma que reglamentariamente se determine; la Ley 13/2002, de 15 de julio, de Fundaciones de Castilla y León, prevé, en su art. 32.2, que corresponderá a los órganos de la Administración autonómica que reglamentariamente determine la Junta de Castilla y León; la Ley 4/2008, de 24 de abril, incorpora la redacción del Código Civil, cuyo art. 3.361.1 indica que el protectorado ejerce sus funciones por medio del departamento de la Generalidad que las tenga atribuidas; la Ley 12/2006, de 1 de diciembre, de Fundaciones de Galicia, atribuye, en su art. 47.2, el protectorado a los departamentos de la Xunta de Galicia que tengan atribuidas las competencias correspondientes a los fines de las fundaciones; la Ley 1/1998, de 2 de marzo, de Fundaciones de Madrid, asigna, en su art. 28.3, el protectorado a las consejerías que reglamentariamente se determine; la Ley 12/1994, de 17 de junio, de Fundaciones del País Vasco, establece, en su art. 36.3, que el protectorado será ejercido por la Administración General de la Comunidad Autónoma del País Vasco, a través del Departamento de Justicia, y la Ley 1/2007, de 12 de febrero, de Fundaciones de La Rioja, dispone, en su art. 41.2, que corresponde al órgano de la administración autonómica que determine reglamentariamente el gobierno de La Rioja. 
E interviene también para instar la resolución judicial motivada que se puede solicitar por el patronato o por el protectorado si no hubiese acuerdo del patronato o éste no fuese ratificado por el protectorado, lo que conduce al siguiente epígrafe.

Ahora bien, antes de entrar en la intervención judicial, dado que la causa «imposibilidad de realización del fin fundacional» admite muy diversas hipótesis, se hace preciso examinar cuáles pueden ser las posibilidades reales de actuación del protectorado a la vista de lo recién expuesto.

En un escenario de inactividad periódica de una fundación, con falta de rendición de cuentas anuales, con inatención de requerimientos, determinando, en suma, la imposibilidad de la fundación de realizar su fin, los cauces jurídicos que prevén la Ley de Fundaciones y su reglamento serían, en síntesis, los siguientes:

- La falta del desempeño del cargo de patrono con la diligencia de un representante leal puede dar lugar al ejercicio de una acción de responsabilidad contra el mismo a ejercer por el protectorado (art.17.3 de la Ley). Entablada tal acción, cabe la suspensión cautelar del patrono afectado (art.18.3 de la Ley).

- Obtenida tal declaración, el patrono puede ser cesado [art.18.2.d) de la Ley], lo que requiere nueva acción judicial, y el protectorado puede sustituirlo temporalmente en tanto se proceda a la pertinente modificación estatutaria (art.18.1 de la Ley).

- Cuando la fundación no puede actuar satisfactoriamente, el protectorado puede exigir al patronato la modificación de estatutos y, en su defecto, instarla judicialmente, como antes se ha visto, salvo que el fundador se oponga a este extremo.

- Igualmente, si la fundación no puede alcanzar sus fines, el protectorado puede exigir al patronato la fusión con otra que lo acepte (y que sea de análogos fines) y, en su defecto, instarla judicialmente, como antes hemos apuntado, y salvo que el fundador se oponga a este extremo.

- En defecto de los dos últimos procedimientos, y cuando resulte imposible alcanzar sus fines, el protectorado puede instar la extinción de la fundación [art. 32.2 en relación con el art.31.c) de la Ley].

- Cuando concurran graves irregularidades en la gestión económica cabe también instar judicialmente la intervención temporal de la fundación por el protectorado (art. 42 de la Ley).

En todos estos casos la ley, en ocasiones de modo explícito y en otras de modo implícito, entiende que el protectorado puede actuar de oficio o 
a instancia de terceros interesados que así lo soliciten ( $v$. gr., otros patronos, beneficiarios posibles, etc.).

Ahora bien, como se ha indicado, la extinción es la «última ratio», y ello debido fundamentalmente al intervencionismo de la Administración sobre asuntos de la esfera —en principio- privada que supone, que puede resultar no ser bien recibido por la autoridad judicial. Por tal motivo, el planteamiento de esta solución sólo puede realizarse cuando, intentados todos los medios posibles de actuación del protectorado o constatada la inutilidad de éstos, no quepa otra opción menos gravosa. Partiendo de tal premisa, cabe concebir la aplicación, a contemplar de manera gradual de ser factible el uso paulatino de las distintas opciones, del siguiente itinerario:

a) En el caso de que los patronos no ejerzan su función, cabría ejercer la acción de responsabilidad contra todos ellos o contra cada uno individualmente, previa conminación a la justificación de su conducta o al desempeño de su cargo. Ello puede conllevar a su sustitución temporal y, a la larga, a su cese (con las responsabilidades civiles a que pueda haber lugar), todo ello con la mira puesta en el cambio de la parte ineficiente del patronato y su sustitución por otro que permita el recto cumplimiento del fin fundacional.

El problema práctico es que, llegados al ejercicio de acciones judiciales, gravosas de por sí, resultaría necesario al menos entablar dos procesos: por un lado, el de declaración de responsabilidad y, por otro, el de cese, y en el caso de oposición, amén de las complicaciones de orden procesal, la posibilidad de costas y la elevada litigiosidad de ello resultante, cabría que tan complejo actuar resultase en la necesidad de ejercer una tercera acción, la de extinción propiamente dicha.

b) Si existe un patronato mínimamente activo se puede exigir, si el fundador no se opuso, la modificación o fusión. Las ventajas de esta vía son evidentes, pues sin oposición del patronato se garantiza, o al menos se procura inicialmente, la viabilidad de la fundación, y con oposición de los patronos se precisaría sólo del ejercicio de una acción judicial de posible éxito que cumpla con tal fin, al tiempo que en el caso de la fusión se permite eliminar fundaciones inactivas y reconducir sus bienes a otras que lo estén y que acepten la fusión.

c) Las graves irregularidades en la gestión económica «que pongan en peligro la subsistencia de la fundación» $(v . g r$., no presentar cuentas reiteradamente), o cuando se aprecie divergencia entre fines y actividades de la misma, permiten la intervención temporal con el fin de remediar la situación. Ello permite designar un nuevo patronato -mediando autorización 
judicial en los términos del art. 42 de la Ley—que examine la situación y actúe en consecuencia.

De esta interesante fórmula, que igualmente requeriría sólo el ejercicio de una acción judicial y que no debemos confundir con la actuación del protectorado en caso de ausencia del patronato, a la que luego nos referimos, podría resultar que el patronato interventor apreciase diversos extremos, como la posibilidad de fusión o la inviabilidad de la fundación, proponiendo las medidas al efecto, y que así se acordase por el patronato, por el protectorado o por la autoridad judicial, según los casos.

El problema de esta vía es, por un lado, cuándo se entiende que la «subsistencia de la fundación» ${ }^{35}$ está en peligro, concepto abierto a muchas interpretaciones que puede chocar con la que finalmente entienda procedente el juez que conozca del asunto, en defecto de acuerdo. Y, por otro lado, que la utilidad de esta vía residiría precisamente en que el patronato interventor determinase si caben fórmulas que permitan la viabilidad o si, por el contrario, lo procedente es extinguir y que este mismo patronato acordase lo uno o lo otro. Esta posibilidad no se contempla expresamente en la Ley, mas el art. 35.3 del reglamento, al regular la propuesta del protectorado, no constriñe las medidas a plantear ni los motivos que las fundan, lo que permite su planteamiento a un juez, siempre justificándosele exhaustivamente la situación.

Sin embargo, la configuración legal como temporal de esta intervención, y su sujeción al plazo y términos que el juez marque, abogan por la interpretación contraria ${ }^{36}$ y que, por tanto, este patronato temporal ejercido por el protectorado deba ceñirse a soluciones que garanticen la continuidad, aun cuando las mismas bien puedan pasar por una modificación

35 V. Cuñat Edo, en J. Olavarría Iglesia (coord.), Comentarios a la Ley de Fundaciones, Valencia, Tirant lo Blanch, 2008, p. 968, tilda esta medida de «hipótesis excepcional» cuya finalidad no es otra que garantizar la subsistencia de la fundación frente a actuaciones gravemente irregulares. Añade el autor que debe tratarse de situaciones excepcionales de puesta en peligro de la existencia misma de la fundación (p. 970).

36 V. CuÑAT EDO, op. cit., pp. 974 y 975, indica que se trata de una medida — por definición - temporal y excepcional, y que debe interpretarse restrictivamente, y que el protectorado debe asumir los poderes del patronato mediante una intervención limitada a lo reparador o de reconducción (p. 977, nota a pie), sin que, en consecuencia, se extienda a lo extintivo. I. Peñalosa Esteban y T. Sanjurjo González, en R. de Lorenzo, J. L. Piñar y T. SAnjurjo (dirs.), Tratado de Fundaciones, Navarra, Aranzadi, 2010, p. 242, con cita de PIÑAR, entienden además que esta situación y la excepcionalidad de la intervención deben estar exhaustivamente fundadas en informe pericial, que el protectorado puede obtener por diversas vías [con cita de los arts. 22, 42.c) y 46.e) del Reglamento] de expertos independientes o de sus funcionarios. 
estatutaria o incluso por una fusión, soluciones que cabe entender continuistas y no extintivas. Ello no obstante, se entiende que si concurre manifiestamente la imposibilidad de realizar el fin fundacional, en cualquier caso la decisión extintiva la debe acordar el juez, lo que en sí constituye la garantía necesaria para que el patronato interventor pueda pedirla, y el juez en su caso acordarla, si no cabe otra solución.

Por ende, las dudas que esta opción plantea, en el orden ya procesal, es si cabe su petición por vía incidental, pues quizá lo procesalmente correcto es plantear un proceso aparte tendente a la extinción, aprovechando la existencia del patronato interventor, opción no exenta de polémica, dado el carácter interino de las funciones de este patronato así designado.

d) La inexistencia de un patronato activo, la imposibilidad de localizar a sus miembros o la inutilidad de hacerlo, la imposibilidad de uso de procedimientos de modificación, fusión o intervención, o su constatada inutilidad, conducen a que el único cauce posible sea el de extinción.

La posibilidad de que el protectorado la inste tras la inacción del patronato frente a su previo requerimiento está fuera de toda duda, al permitirlo con claridad el art. 38.2 del reglamento, siempre condicionado su uso a una prueba indubitada de la «imposibilidad de realizar el fin fundacional», concepto, nuevamente, abierto a muchas interpretaciones - detalladas en anteriores epígrafes - no siempre favorables a lo que el protectorado opine.

Ahora bien, llegados al punto en que se acuerde judicialmente la extinción, nos encontramos con una laguna normativa que examinaremos al final de este trabajo, al no preverse que el protectorado pueda liquidar directamente el patrimonio de una fundación sin órgano de gobierno real y propio.

e) Una última opción, no desarrollada en extenso pero prevista en el art. 35.1.g) de la Ley de Fundaciones, sería la de que el protectorado ejerciese provisionalmente las funciones del órgano de gobierno de la fundación cuando todos los llamados a ejercerlo, por cualquier motivo, faltasen.

La llamada por la Ley a un ejercicio provisional por la Administración de funciones de gobierno de una entidad privada lleva por sí misma a considerar que, al menos, resulta forzado entender que desde la propia Administración pueda acabar instándose la extinción de la misma, aun con el refuerzo que suponga que legalmente ejerza su gobierno por inexistencia de un patronato efectivo. Ahora bien, la medida es factible ${ }^{37}$

37 En este sentido, V. Cuñat Edo, op. cit., p. 882, señala que, además de deber entenderse que este ejercicio provisional por el protectorado no tiene por qué serlo directo, mas 
y, en la medida en que esa falta de gobierno, sumada a la imposibilidad de uso de cualquiera de los cauces descritos anteriormente, evidencie la imposibilidad real de alcanzar los fines fundacionales, es evidente que la solución extintiva resultará aconsejable, y teniendo en cuenta que - tanto se adopte la decisión por un patronato propio como por un protectorado que ejerza de patronato- la extinción sólo podrá acordarla el juez, será facultad del mismo el apreciar, en atención a las circunstancias fácticas concurrentes, si es esta solución la que debe adoptarse, quedando, en consecuencia, cubierta por la obligada asistencia judicial, que enervaría cualquier atisbo de intervención desmedida y podría amparar esta solución plenamente ${ }^{38}$.

\section{Intervención de la autoridad judicial}

En cuanto al órgano judicial que ha de intervenir dictando una resolución motivada cuando concurra esta causa de extinción en el caso de falta de acuerdo del patronato o de negativa del protectorado a ratificar el que éste hubiera adoptado, la Sentencia del Tribunal Supremo de fecha 4 de julio de 2005 (Ar. 6900) considera que el órgano competente es el juez de primera instancia del domicilio de la fundación.

El Tribunal Supremo llega a tal conclusión aplicando tanto la Ley 30/1994, que era la vigente en el momento en que se produjeron los hechos, como acudiendo a la Ley de Fundaciones de 2002 que había entrado en vigor al tiempo de dictar sentencia. En efecto, declara que ha sido el propio legislador el que ha venido a confirmar que el art. 30.4 de la Ley 30/1994 (que advierte que será el Juzgado de Primera Instancia del domicilio de la fundación el llamado a tomar estas decisiones y que deberá hacerlo siguiendo lo dispuesto para los incidentes en la Ley de Enjuiciamiento Civil) contiene una regla especial respecto de la general de su art. 35. Y reconoce que la vigente Ley de Fundaciones mantiene el

sí que implica responsabilizarse de esta gestión, esta acción provisional debe estar «encaminada a la subsistencia de la fundación o al menos a la regular sumisión de ésta a la ley, que según las circunstancias puede conducir a su reposición a situación de normalidad, o bien a su extinción, si concurren causas para ello».

38 Señala J. L. Piñar Mañas, en R. De Lorenzo, J. L. Piñar y T. Sanjurjo (dirs.), Tratado de Fundaciones, op. cit., p. 97, tras una fuerte crítica a la actual configuración y dispersión de protectorados, que: «En cualquier caso es evidente que a los tribunales les corresponde el control último de la legalidad de la actuación de las fundaciones y de la Administración. Ningún problema hay en ello». 
mismo régimen que en la anterior en su art. 43, que sistematiza el régimen de recursos jurisdiccionales remitiendo al orden contencioso frente a los actos del protectorado y a los de calificación del Registro, que ponen fin a la vía administrativa (puntos 1 y 2) y al orden civil, y concretamente al Juzgado de Primera Instancia del domicilio de la fundación, para conocer por el declarativo que corresponda de las pretensiones a las que se refieren los arts. 9.4; 13.2; 17.3; 18.2.d); $18.3 ; 29.3 ; 30.4 ; 32.2$, 3 y $4 ; 35.2$, y 42.2 (punto 3 ).

Para explicar la razón por la que corresponde al Juzgado de Primera Instancia del domicilio de la fundación dictar una resolución motivada cuando concurra esta causa de extinción en el caso de falta de acuerdo del patronato o de negativa del protectorado a ratificar el que éste hubiera adoptado, el Tribunal Supremo acude a la Sentencia de fecha 20 de diciembre de 2003 (Ar. 614 de 2004) que indica que, dada la naturaleza privada de las fundaciones, sus litigios, en principio, están comprendidos dentro del ámbito jurisdiccional del orden civil delimitado por el art. 22.1.1. ${ }^{\circ}$ de la Ley Orgánica del Poder Judicial. Continúa esta sentencia indicando que, precisamente por ser privada la naturaleza de las fundaciones, la intervención del protectorado en lo relativo a su constitución se orienta más a la constatación de los elementos estructurales exigidos legalmente para su nacimiento. En cambio, la que se ocupa de su funcionamiento consiste en la vigilancia de que la actuación externa de la fundación en cuanto persona jurídica no se aparte de los intereses generales que encarna. Eso hacía, continúa la sentencia, que las controversias internas de una fundación privada no fueran distintas de las que suscita cualquier otra figura personificada de Derecho privado, como lo confirman las reiteradas llamadas a la jurisdicción civil que contienen tanto la antigua como la actual Ley de Fundaciones.

Para el Tribunal Supremo, el protectorado interviene para ratificar la decisión extintiva del patronato cuando se hubiere alcanzado el fin fundacional, sea imposible realizarlo o concurra cualquier otra causa prevista en los estatutos. Y de darse alguna de estas causas de extinción y no ratificar el protectorado el acuerdo del patronato o de no existir este acuerdo, será la autoridad judicial la que, en resolución motivada, supla la falta de acuerdo del patronato o la negativa del protectorado a ratificar el que éste hubiere adoptado. Autoridad judicial que también ha de intervenir dictando una resolución motivada cuando concurra cualquier otra causa de extinción prevista legalmente y distinta de las relacionadas en el art. 29. 
Prosigue el Tribunal Supremo en esta línea indicando que, tratándose de acordar la extinción de la fundación, es la voluntad del patronato la que cuenta y, en su defecto, la del juez civil, lo cual es coherente no sólo con la naturaleza de la fundación, sino también con las garantías con las que el art. 34 de la Constitución rodea el ejercicio del derecho de fundación.

Esta interpretación persigue, en esencia, evitar la duplicidad de jurisdicciones (por un lado, la civil, por otro, la contencioso-administrativa), lo que la vigente Ley de Fundaciones consagra con claridad en su art. 43, señalando el orden jurisdiccional competente para conocer cada tipo de acto y atribuyendo al orden civil el conocimiento de cuestiones que, si bien provienen de la Administración actuando a través del protectorado, deben ser conocidas por el juez y además por el juez civil, dada la naturaleza privada de las fundaciones y su personalidad jurídica propia.

En definitiva, los actos del protectorado que ponen fin a la vía administrativa son impugnables ante esta jurisdicción excepto en los casos en los que la propia ley los somete al conocimiento de la jurisdicción civil.

Una parte de las leyes autonómicas ${ }^{39}$ también atribuyen al Juzgado de Primera Instancia del domicilio de la fundación la competencia para conocer, de acuerdo con los trámites del proceso declarativo que corresponda, de las pretensiones a que se refieran, entre otros artículos, el que trata de la extinción de las fundaciones por imposibilidad de realización del fin fundacional, en los casos en que se puede instar la resolución judicial motivada. Pero no faltan las leyes autonómicas que establecen que los actos del

39 La Ley 10/2005, de 31 de mayo, de Fundaciones de Andalucía, así lo recoge en su art. 48; la Ley 2/1998, de 6 de abril, de Fundaciones de Canarias, establece, en su art. 38, que los actos del protectorado de fundaciones canarias que pongan fin a la vía administrativa serán impugnables ante la jurisdicción contencioso-administrativa; la Ley 13/2002, de 15 de julio, de Fundaciones de Castilla y León, no lo regula, si bien, en relación con la extinción, se remite a la legislación estatal; la Ley 8/1998, de 9 de diciembre, de Fundaciones de la Comunidad Valenciana, establece, en su art. 30, que los actos del protectorado ponen fin a la vía administrativa y son impugnables en los términos previstos en el art. 43 de la Ley 50/2002, de 26 de diciembre, de Fundaciones; la Ley 12/2006, de 1 de diciembre, de Fundaciones de Galicia, establece, en su art. 51, que los acuerdos del protectorado sujetos a Derecho administrativo serán recurribles en vía administrativa y, en su caso, ante la jurisdicción contencioso-administrativa; la Ley 1/1998, de 2 de marzo, de Fundaciones de Madrid, no lo establece; la Ley 12/1994, de 17 de junio, de Fundaciones del País Vasco, dispone, en su art. 39, que los actos del protectorado que agoten la vía administrativa serán impugnables en el orden jurisdiccional contencioso-administrativo conforme a la legislación en vigor, y la Ley 1/2007, de 12 de febrero, de Fundaciones de La Rioja, prevé, en su art. 51, que los actos del protectorado ponen fin a la vía administrativa y serán impugnables ante el orden jurisdiccional contencioso-administrativo. 
protectorado ponen fin a la vía administrativa y serán impugnables ante el orden jurisdiccional contencioso-administrativo.

En definitiva, el órgano judicial que ha de intervenir dictando una resolución motivada cuando concurra esta causa de extinción ha de llevar a cabo la intervención indicada cuando el acuerdo de extinción del patronato no fuera ratificado por el protectorado, lo que ha de instarse por el propio patronato, o cuando el protectorado estimase de oficio que concurre la causa de extinción que se trata y el patronato no acordase la extinción de la fundación, en cuyo caso la resolución judicial ha de instarse por el protectorado, tal y como prevé la Ley de Fundaciones.

La Ley de Fundaciones supone, en este punto, el desarrollo del art. 34.2 de la Constitución, que se remite a lo dispuesto en los apartados 2 y 4 del art. 22, el segundo de los cuales dispone que las asociaciones sólo podrán ser disueltas o suspendidas en sus actividades en virtud de resolución judicial motivada, que no puede entenderse como una exigencia de resolución judicial para la extinción de la fundación en todos los casos, sea cual fuera la causa de extinción, sino para el caso de que no hubiese acuerdo entre el patronato y el protectorado sobre la producción del supuesto de hecho extintivo, en relación con el caso que nos ocupa.

\section{LIQUIDACIÓN DE LAS FUNDACIONES}

La doctrina pone de manifiesto ${ }^{40}$ que una vez que se extingue la fundación por imposibilidad de realización del fin fundacional, mediante acuerdo del patronato ratificado por el protectorado, o por resolución judicial en los casos en que la misma se puede instar, se produce la apertura del procedimiento de liquidación de la misma. El procedimiento de liquidación se tramita durante un periodo que se considera una fase intermedia de la fundación, previa a la total desaparición de la misma, durante la cual la fundación mantiene su personalidad jurídica y el patronato continúa siendo el órgano de gobierno bajo la supervisión del protectorado pero que comprende no los actos de la actividad cotidiana, sino las actuaciones precisas para liquidar: cobro de créditos pendientes, pago de deudas y, como medio para esto, realización de los bienes, en la medida en que sea necesario.

40 J. CafFarena Laporta, op. cit., pp. 479 y ss.; M. L. Ortiz VaAmonde, op. cit., pp. 137 y ss.; M. ${ }^{a}$ de L. Ferrando Villalba, en J. Olavaria Iglesia (coord.), Comentarios a la Ley de Fundaciones, Valencia, Tirant Lo Blanch, 2008, pp. 834 y ss., y T. GonZÁlez Cueto, op. cit., pp. 245 y ss. 
Este procedimiento se regula en el art. 33 de la Ley de Fundaciones, que establece, en el sentido indicado, en su apartado 1, que la extinción de la fundación, salvo en el supuesto previsto en el art. 31.d), determinará la apertura del procedimiento de liquidación, y que el mismo se realizará por el patronato de la fundación bajo el control del protectorado. La salvedad se refiere a la extinción por fusión en que las operaciones que comprende la liquidación de la fundación no son necesarias porque los bienes y derechos de la fundación que desaparece van a parar a la fundación absorbente (en la fusión por absorción) o a la nueva fundación que resulta (en la fusión por constitución). El apartado 4 de dicho precepto dispone que «reglamentariamente se establecerán los criterios reguladores del procedimiento de liquidación a que se hace referencia en los apartados anteriores».

\section{Destino de los bienes y derechos resultantes de la liquidación}

El art. 33 de la Ley de Fundaciones, en sus apartados 2 y 3 , reproduce lo señalado por el art. 31.2 y 3 de la anterior Ley 30/1994, al prever que: «2. Los bienes y derechos resultantes de la liquidación se destinarán a las fundaciones o a las entidades no lucrativas privadas que persigan fines de interés general y que tengan afectados sus bienes, incluso para el supuesto de su disolución, a la consecución de aquéllos, y que hayan sido designados en el negocio fundacional o en los Estatutos de la fundación extinguida. En su defecto, este destino podrá ser decidido, a favor de las mismas fundaciones y entidades mencionadas, por el patronato cuando tenga reconocida esta facultad por el fundador y, a falta de esta facultad, corresponderá al protectorado cumplir ese cometido». Si bien con la particularidad de que: «3. No obstante lo dispuesto en el apartado anterior, las fundaciones podrán prever en sus Estatutos o cláusulas fundaciones que los bienes y derechos resultantes de la liquidación sean destinados a entidades públicas, de naturaleza no fundacional, que persigan fines de interés general».

\section{A. Posibilidad o no de reversión de los bienes y derechos al fundador}

La cuestión que plantea este precepto y que se ha cuestionado por la doctrina y los Tribunales de Justicia es si posibilita o no la reversión de los bienes y derechos al fundador o las personas que designe éste. 
La doctrina ${ }^{41}$ explica que con anterioridad a la entrada en vigor de la Ley 30/1994 y de la Ley 50/2002, la cuestión se resolvía por aplicación del art. 39 del Código Civil, que al indicar: «Si por haber expirado el plazo durante el cual funcionaban legalmente o por haber realizado el fin para el cual se constituyeron, o por ser ya imposible aplicar a éste la actividad y medios de que disponían, dejasen de funcionar las corporaciones, asociaciones y fundaciones, se dará a sus bienes la aplicación que las leyes, o los estatutos, o las cláusulas fundacionales, les hubiesen en esta previsión asignado. Si nada se hubiese establecido previamente, se aplicarán esos bienes a la realización de fines análogos en interés de la región, provincia o municipio que principalmente debieran recoger los beneficios de las instituciones extinguidas», se entendía no obstaculizaba la reversión de los bienes fundacionales una vez que la fundación se extinguía.

La doctrina y la jurisprudencia españolas habían reconocido de forma casi unánime la eficacia de las cláusulas de reversión al examinar el art. 39 del Código Civil, haciendo prevalecer la necesidad de respetar el principio de autonomía de la voluntad del fundador en lo que se refiere al destino de los bienes una vez extinguida la fundación, permitiendo el retorno de los bienes dotacionales a las personas designadas por los fundadores, dentro de los límites de la sustitución fideicomisaria contemplados por el art. 781 del Código Civil ${ }^{42}$.

Como exponentes de la jurisprudencia cabe citar las Sentencias del Tribunal Supremo de fechas 23 de junio de 1964 (Ar. 3682) y de 6 de junio de 1987 (Ar. 4744). Esta última declara que: «Si en este caso de extinción de la fundación, el art. 39 CC prevé el destino de los bienes conforme a la voluntad del fundador, prevalente sobre las disposiciones de la ley, a lo dicho por su manifestación expresa habrá de estarse [...]. Por lo tanto, rige, en primer lugar, la voluntad expresa del fundador». Y añade que al disponer el art. 39 CC que «cuando dejasen de funcionar las corporacio-

${ }^{41}$ T. González Cueto, op. cit., pp. 245 y ss.; I. Trapiella Nieto, en A. Real Pérez (dir.), Constitución y extinción de fundaciones, Valencia, Tirant Lo Blanch, 1999, pp. 264 y ss.

${ }^{42}$ Sin embargo, la Sentencia de la Audiencia Nacional de fecha 28 de septiembre de 2005 (JUR 2005\262473) considera, en un supuesto de reversión a la fundación, que lo dispuesto en los arts. 781 y 785.2 CC en sede de sustituciones fideicomisarias, relativo a la nulidad de las prohibiciones de disponer que excedan del segundo grado, no puede ser aplicable a las fundaciones que se constituyen como personas jurídicas con voluntad de duración indefinida, siendo así que de existir alguna vinculación patrimonial contraria al ordenamiento jurídico ésta sería la que deriva del respeto al cumplimiento del fin de interés general, por lo que, operada la reversión, desparece cualquier vínculo real existente al que el bien objeto de dotación se halla afectado. 
nes, asociaciones y fundaciones, se dará a sus bienes la aplicación que las leyes, o los estatutos, o las cláusulas fundacionales, les hubiesen en esta previsión asignado», tal orden no otorga preferencia a la ley y los estatutos frente a las cláusulas fundacionales, sino que al exponer dicho orden se está refiriendo, respectivamente, a las normas que rigen las corporaciones, las asociaciones y las fundaciones.

Ahora bien, después de la entrada en vigor de la Ley 50/2002 se pueden distinguir dos posiciones: la primera, mantenida por algún autor ${ }^{43}$ y algún Tribunal de Justicia, favorable a la posibilidad de reversión, y la segunda, mantenida por la doctrina mayoritaria y por varios Tribunales de Justicia, que consideran que tal ley no la permite.

De la primera postura es reflejo la Sentencia de la Audiencia Nacional de fecha 28 de septiembre de 2005 (JUR 2005\262473), que considera que el contenido del art. 31.2 de la Ley 30/1994, el cual se refiere propiamente al destino de los bienes en caso de extinción de la fundación, no excluye la cláusula reversional. Los argumentos que emplean Trapiella y la Audiencia Nacional son los siguientes:

a) El respeto a la voluntad del fundador, porque en el ámbito de las fundaciones dicha voluntad explicita, delimita y justifica el fin de interés general objeto de persecución mediante la dotación patrimonial que se personifica.

b) En el art. 1.1 de la antigua Ley de Fundaciones y en el art. 2.1 de la hoy vigente se habla de una afectación duradera, pero no perpetua ni irreversible ni irrevocable, ni que los bienes y derechos dotados no puedan, cumplido un término, o un evento determinado, o la finalidad para la que fueron destinados, ser recuperados por el fundador o sus causahabientes.

c) El disfrute de los beneficios fiscales previstos en la Ley 30/1994 requería aplicar el patrimonio, en caso de disolución, a la realización de fines de interés general análogos a los realizados por las fundaciones. Pero ese requisito no se exige para la existencia de toda fundación, y la fundación que no cumpla con el mismo no deja de existir ni es ilícita, sino sólo se verá privada de los beneficios fiscales que prevé la ley.

d) La jurisprudencia del Tribunal Supremo en supuestos análogos que se concreta en las sentencias ya expuestas al tratar la situación anterior a las Leyes de Fundaciones de 1994 y 2002, y el criterio de la doctrina mayoritaria que interpretó la normativa de aplicación al caso antes de las Leyes de Fundaciones de 1994 y de 2002.

${ }^{43}$ I. Trapiella Nieto, op. cit., pp. 264 y ss. 
La segunda postura, mantenida por la doctrina mayoritaria ${ }^{44}$, por el Tribunal Supremo en la Sentencia de fecha 9 de diciembre de 2008 (Ar. 8079) y por la Audiencia Provincial de Álava en la Sentencia de fecha 14 de julio de 2008 (AC 2008\2014), entiende que el tenor literal del art. 33.2 y 3 de la Ley 50/2002, de Fundaciones, y del art. 35 de la Ley de Fundaciones del País Vasco de 17 de junio de 1994 excluyen la posibilidad de reversión. Los argumentos que emplean son los siguientes:

a) Según la sentencia del Tribunal Supremo referida, nos encontramos ante un régimen jurídico claro, la Ley 50/2002, y más concretamente lo dispuesto en su art. 33, y la obligación de adaptación de unos estatutos al nuevo orden legal. No se trata de ninguna aplicación retroactiva de la ley, pues ésta no regula situaciones anteriores, sino que mira al futuro regulando el estatuto jurídico de las fundaciones a partir de su entrada en vigor y concediendo un plazo de tiempo para su adaptación, y lo contrario implicaría la inaplicación de toda la Ley 50/2002, y no sólo su art. 33, a las fundaciones constituidas con anterioridad a su entrada en vigor.

b) La Sentencia de la Audiencia Provincial de Álava de fecha 14 de julio de 2008 interpreta el art. 35 de la Ley de Fundaciones del País Vasco de 17 de junio de 1994, que también en su sentido literal limita el destino de tales bienes a entidades o actividades de interés general y a fundaciones o entidades que persigan fines análogos, y aprecia que, en el momento en que se ejercitó la acción a los efectos de la extinción de la fundación estaba ya en vigor la referida ley, que hace inviable la reversión establecida por el fundador; reversión que no es sino una expectativa no consolidada.

c) La doctrina antes apuntada defiende la irrevocabilidad de la dotación, el carácter perpetuo de la afectación patrimonial de la dotación al interés público, sin perjuicio de su disponibilidad para el tráfico jurídico y de la admisión de las fundaciones temporales, así como la inadmisibilidad de las cláusulas de reversión, por ser contrarias a la ley y a la propia naturaleza de la fundación.

d) En consonancia con lo anterior, el art. 3 de la Ley 49/2002, de 23 de diciembre, de régimen fiscal de las entidades sin fines lucrativos y de los incentivos fiscales al mecenazgo, al establecer los requisitos que se han de

${ }^{44}$ M. a L. Ortiz VaAmonde, op. cit., pp. 137 y ss.; T. GonZÁlez Cueto, op. cit., pp. 245 y ss.; J. Caffarena Laporta, op. cit., pp. 479 y ss.; M. ${ }^{a}$ de L. Ferrando Villalba, op. cit., pp. 834 y ss.; Nieto Alonso, op. cit., y R. Durán Rivacoba, Fundaciones. Problemas actuales y reforma legal, Navarra-Principado de Asturias, Aranzadi-Fundación María Cristina Masaveu Peterson, 2011, pp. 269 y ss. 
cumplir para tener la consideración de entidad sin fines lucrativos a efectos fiscales, prevé que «en ningún caso tendrán la condición de entidades sin fines lucrativos, a efectos de esta ley, aquellas entidades cuyo régimen jurídico permita, en los supuestos de extinción, la reversión de su patrimonio al aportante al mismo o a sus herederos o legatarios, salvo que la reversión esté prevista a favor de alguna entidad beneficiaria de mecenazgo a los efectos previstos en los arts. 16 a 25 , ambos inclusive, de esta ley».

La postura mantenida por la doctrina mayoritaria y por las sentencias referidas es la que se considera más acertada porque los argumentos que se han expuesto son los que permiten una interpretación del art. 33 de la Ley de Fundaciones de acuerdo con lo dispuesto en el art. 3.1 del Código Civil, según el sentido propio de sus palabras (pues del tenor literal del mismo resulta que los bienes y derechos resultantes de la liquidación deben destinarse a las entidades que indica), en relación con el contexto de acuerdo con una interpretación sistemática (poniendo en conexión tal precepto con el art. 3 de la Ley 49/2002, de 23 de diciembre, que si bien establece la previsión ya expuesta a efectos fiscales, se refiere a las fundaciones atendiendo al concepto de las mismas que se ha expuesto en el correspondiente apartado de este estudio), atendiendo a su espíritu y finalidad (la consideración de la dotación como irrevocable y el carácter perpetuo de la afectación de la dotación al interés público, sin perjuicio de la admisión de las fundaciones temporales).

Lo expuesto hasta ahora en este epígrafe es aplicable a las fundaciones de competencia estatal. En cuanto a las fundaciones autonómicas ha de estarse a lo que prevén las leyes autonómicas, la mayoría de las cuales ${ }^{45}$ establece el mismo destino para los bienes y derechos resultantes de la liquidación en términos idénticos o muy semejantes a los que recoge la Ley de Fundaciones estatal, esto es, que se destinarán a las fundaciones o a las entidades no lucrativas privadas que persigan fines de interés

${ }^{45}$ La Ley 10/2005, de 31 de mayo, de Fundaciones de Andalucía, así lo establece en su art. 43; la Ley 2/1998, de 6 de abril, de Fundaciones de Canarias, lo recoge en términos similares en su art. 33; la Ley 13/2002, de 15 de julio, de Fundaciones de Castilla y León, lo prevé en términos semejantes en su art. 31; la Ley 4/2008, de 24 de abril, que modifica el Código Civil de Cataluña, redacta el art. 3.356 para destinar los bienes y derechos resultantes de la liquidación a fundaciones y entidades análogas; la Ley 8/1998, de 9 de diciembre, de Fundaciones de la Comunidad Valenciana, lo dispone en su art. 26, si bien prevé que las fundaciones constituidas por personas jurídico-públicas puedan prever en sus Estatutos que los bienes y derechos resultantes de la liquidación reviertan a su fundador; la Ley 12/1994, de 17 de junio, de Fundaciones del País Vasco, lo recoge en su art. 35, y La Ley 1/2007, de 12 de febrero, de Fundaciones de La Rioja, lo establece en su art. 40. 
general, que tengan afectados sus bienes, incluso para el supuesto de su disolución, a la consecución de aquéllos, que hayan sido designados en el negocio fundacional o en los estatutos de la fundación extinguida, y que desarrollen sus actividades principalmente en la Comunidad Autónoma correspondiente. En su defecto, este destino podrá ser decidido a favor de las mismas fundaciones y entidades mencionadas por el patronato cuando tenga reconocida esta facultad por el fundador, y, a falta de esa facultad, corresponderá al protectorado cumplir ese cometido. No obstante lo anterior, las fundaciones podrán prever en sus estatutos o cláusulas fundacionales que los bienes y derechos resultantes de la liquidación sean destinados a entidades públicas de naturaleza no fundacional, siempre que persigan fines de interés general.

Sin embargo, y como excepciones reseñables, la Ley 8/1998, de 9 de diciembre, de Fundaciones de la Comunidad Valenciana, prevé, en su art. 26.3, que las fundaciones constituidas por personas jurídico-públicas podrán prever en sus estatutos que los bienes y derechos resultantes de la liquidación reviertan a su fundador; la Ley 12/2006, de 1 de diciembre, de Fundaciones de Galicia, establece, en su art. 45, que a los bienes y derechos resultantes de la liquidación de una fundación extinguida se les dará el destino previsto por el fundador o decidido por el patronato cuando tenga reconocida esta facultad en la carta fundacional, y si no hubiera previsión del fundador ni facultad del patronato, se les dará un destino análogo al previsto en la mayoría de las leyes autonómicas, y la Ley 1/1998, de 2 de marzo, de Fundaciones de Madrid, dispone, en su art. 27, que a los bienes y derechos resultantes de la liquidación de una fundación extinguida se les dará el destino previsto por el fundador, y en el supuesto de que el fundador no haya previsto este destino, el mismo será decidido en primer término por el patronato, cuando tenga reconocida esta facultad, y a falta de ésta, corresponderá al protectorado cumplir ese cometido destinándose en este segundo supuesto a las fundaciones o entidades análogas a las previstas en la mayoría de las leyes autonómicas.

El Tribunal Constitucional, en su Sentencia de fecha 21 de diciembre de 2005 (RTC 2005\341), ha declarado la constitucionalidad del art. 27.2 de la Ley 1/1998, de 2 de marzo, de Fundaciones de Madrid, interpretado en los términos expresados en la propia sentencia. Dicha sentencia considera, por una parte, que dicho precepto es respetuoso con las competencias asumidas por la Comunidad Autónoma de Madrid, pues declara que habiendo asumido estatutariamente el legislador autonómico competencia sobre el régimen jurídico de las fundaciones que desarrollen su actividad principal- 
mente en el territorio de la Comunidad Autónoma, dentro de dicha competencia encuentra perfecto acomodo el establecimiento de normas relativas a las actuaciones administrativas procedentes en caso de disolución de entes regulados. Y es de declarar, como hace el precepto legal impugnado, que el destino de los bienes de la fundación en caso de extinción será, en primer término, el decidido por el fundador, y no supone regulación de la posible cesión o transferencia de bienes patrimoniales ni de ningún instituto civil, sino el reconocimiento de la eficacia de tal decisión desde la perspectiva de la liquidación que debe llevar a cabo el patronato, bajo el control del protectorado, según prescribe el art. 27.1 de la Ley autonómica.

La misma sentencia declara, por otra parte, que de la doctrina constitucional elaborada en esta materia no puede deducirse que forme parte de esa imagen recognoscible de la institución preservada por el art. $34 \mathrm{CE}$ la afectación perpetua de los bienes o derechos al servicio de los intereses generales. El interés jurídico protegido por el art. $34 \mathrm{CE}$ exige que los bienes y derechos con que se dote a la fundación sirvan al «interés general» en tanto subsista el ente fundacional, pero no prescribe la permanente afectación tras la extinción de la fundación. De suerte que el mencionado precepto constitucional no cierra las opciones del legislador, puesto que no limita su libertad de configuración de las fundaciones imponiéndole, como contenido esencial del derecho preservado, cuál haya de ser, una vez extinguida, el destino de los bienes y derecho con los que se dote a la fundación. Pero se añade que ello no puede entenderse que permite al fundador hacer previsiones, para después de la extinción de la fundación, que ignoren o contradigan la finalidad de interés general que la Constitución impone como esencia de la naturaleza jurídica de la institución y que, a su vez, se establece también en el Código Civil, en la Ley estatal de Fundaciones y en la propia Ley autonómica impugnada.

\section{B. Entidades destinatarias}

La interpretación sistemática del art. 33 de la Ley 50/2002, de 26 de diciembre, de Fundaciones, permite plantearse si se puede poner en conexión dicho precepto con los arts. 2 y 3 de la Ley 49/2002, de 23 de diciembre, de régimen fiscal de las entidades sin fines lucrativos y de los incentivos fiscales al mecenazgo, a los efectos de determinar lo que se puede considerar que son entidades destinatarias de los bienes y derechos resultantes de la liquidación. 
La Exposición de Motivos de la Ley 49/2002, de 23 de diciembre, se refiere a la finalidad de la ley, declarando al respecto que «en consecuencia, esta ley, dictada al amparo del art. 149.1.14. ${ }^{a}$ de la Constitución y sin perjuicio de los regímenes tributarios forales, tiene una finalidad eminentemente incentivadora de la colaboración particular en la consecución de fines de interés general, en atención y reconocimiento a la cada vez mayor presencia del sector privado en la tarea de proteger y promover actuaciones caracterizadas por la ausencia de ánimo de lucro, cuya única finalidad es de naturaleza general y pública».

La finalidad expresada en atención y reconocimiento a la cada vez mayor presencia del sector privado en la tarea de proteger y promover actuaciones caracterizadas por la ausencia de ánimo de lucro, cuya única finalidad es de naturaleza general y pública, determina que los elementos expresados, que son los que contempla la Ley 50/2002, de 26 de diciembre, de Fundaciones, se tengan en cuenta también por la Ley 49/2002, de 23 de diciembre, que trata, por tanto, la misma cuestión aunque sea a efectos diferentes, por lo que se entiende necesario acudir a las que se consideran entidades sin fines de lucro a los efectos de esta última.

El art. 2 de la Ley 49/2002, de 23 de diciembre, considera entidades sin fines lucrativos a efectos de esta ley, siempre que cumplan los requisitos establecidos en el artículo siguiente:

a) Las fundaciones.

b) Las asociaciones declaradas de utilidad pública.

c) Las organizaciones no gubernamentales de desarrollo a que se refiere la Ley 23/1998, de 7 de julio, de Cooperación Internacional para el Desarrollo, siempre que tengan alguna de las formas jurídicas a que se refieren los párrafos anteriores.

d) Las delegaciones de fundaciones extranjeras inscritas en el Registro de Fundaciones.

e) Las federaciones deportivas españolas, las federaciones deportivas territoriales de ámbito autonómico integradas en aquéllas, el Comité Olímpico Español y el Comité Paralímpico Español.

f) Las federaciones y asociaciones de las entidades sin fines lucrativos a que se refieren los párrafos anteriores.

El art. 33 de la Ley 50/2002, de 26 de diciembre, de Fundaciones, exige, además, que sean privadas y que persigan fines de interés general. El art. 3 de la Ley 49/2002, de 23 de diciembre, impone como requisito, entre 
otros, para considerar, a efectos de esa ley, que la entidad no tiene fines lucrativos: que persiga fines de interés general, como pueden ser, entre otros, los de defensa de los derechos humanos, de las víctimas del terrorismo y actos violentos, los de asistencia social e inclusión social, cívicos, educativos, culturales, científicos, deportivos, sanitarios, laborales, de fortalecimiento institucional, de cooperación para el desarrollo, de promoción del voluntariado, de promoción de la acción social, defensa del medioambiente, de promoción y atención a las personas en riesgo de exclusión por razones físicas, económicas o culturales, de promoción de los valores constitucionales y defensa de los principios democráticos, de fomento de la tolerancia, de fomento de la economía social, de desarrollo de la sociedad de la información, de investigación científica, desarrollo o innovación tecnológica, y de transferencia de la misma hacia el tejido productivo como elemento impulsor de la productividad y competitividad empresarial.

La consideración de las entidades sin fines lucrativos que recoge la Ley 49/2002, de 23 de diciembre, como las entidades que pueden ser destinatarias del haber resultante de la liquidación de las fundaciones contempladas en el art. 33 de la Ley 50/2002, de 26 de diciembre, de Fundaciones, puede defenderse de acuerdo con la interpretación sistemática que permite el art. 3.1 del Código Civil entendida como lo hace la jurisprudencia ${ }^{46}$.

En consecuencia, una interpretación sistemática del art. 33 de la Ley 50/2002, de 26 de diciembre, de Fundaciones, en relación con los arts. 2 y 3 de la Ley 49/2002, de 23 de diciembre, permite entender que las fundaciones o entidades no lucrativas privadas que persigan fines de interés general que pueden ser destinatarias del haber resultante de la liquidación de las fundaciones son las entidades sin fines lucrativos que se contemplan en los arts. 2 y 3 de la Ley 49/2002, de 23 de diciembre.

\section{Procedimiento de liquidación y criterios reguladores del procedimiento de liquidación}

El art. 39 del Real Decreto 1337/2005, de 11 de noviembre, por el que se aprueba el Reglamento de las Fundaciones de Competencia Estatal, regula el procedimiento y los criterios de liquidación en los siguientes términos, que por su interés transcribimos:

46 SSTS de 29 de octubre de 2005 (Ar. 7615) y de 2 de julio de 1991 (Ar. 5319), y ST de la Audiencia Provincial de Guipúzcoa de 15 de febrero de 2000 (AC 2000\206). 
«1. La liquidación de la fundación extinguida se realizará por el patronato bajo el control del protectorado. A tal efecto, el protectorado podrá solicitar del patronato cuanta información considere necesaria, incluso con carácter periódico, sobre el proceso de liquidación.

2. Sin perjuicio de lo previsto en el apartado anterior, el patronato podrá apoderar o delegar la ejecución material de sus acuerdos relativos al proceso de liquidación.

3. El procedimiento de liquidación se inicia con la aprobación por el patronato del balance de apertura de la liquidación.

4. Resultan aplicables al proceso de liquidación los requisitos establecidos con carácter general para los actos dispositivos de los bienes y derechos de la fundación, así como las normas que regulan la responsabilidad de los patronos.

5. El protectorado impugnará ante la autoridad judicial los actos de liquidación que resulten contrarios al ordenamiento jurídico o a los estatutos de la fundación.

6. No se podrán destinar los bienes y derechos resultantes de la liquidación a las entidades a que se refieren los apartados 2 y 3 del art. 33 de la Ley 50/2002, de 26 de diciembre, de Fundaciones, sin que hayan sido satisfechos todos los acreedores o sin haber consignado el importe de sus créditos. Cuando existan créditos no vencidos, se asegurará previamente el pago.

7. La función liquidadora concluirá con el otorgamiento de la escritura de cancelación de la fundación, la solicitud de la cancelación de los asientos referentes a la fundación y su inscripción en el Registro de Fundaciones de competencia estatal».

En consecuencia, la doctrina ${ }^{47}$ considera que se deben efectuar las siguientes actuaciones:

a) Confeccionar y aprobar un inventario y balance de situación de la fundación a fecha de inicio del procedimiento de liquidación, debiendo adjuntar a los mismos la documentación complementaria necesaria.

b) Realizar las operaciones pendientes de cualquier naturaleza que estén iniciadas.

c) Realizar las nuevas operaciones que sean necesarias para la liquidación.

d) Cobrar los créditos pendientes.

e) Pagar a los acreedores por el orden de prelación establecido.

47 R. Bergós, G. Bergós y R. Gómez, Todo sobre las Fundaciones, Madrid, Difusión Jurídica, 2008, p. 103. 
f) Adjudicar los bienes y derechos resultantes de la liquidación en los términos previstos en la ley.

g) Formalizar en escritura pública la extinción, liquidación y adjudicación del haber resultante e interesar la inscripción en el Registro de Fundaciones.

Las leyes autonómicas ${ }^{48}$ también se refieren a las actuaciones a llevar a cabo recogiendo la de cobrar créditos, satisfacer las deudas, formalizar los actos pendientes de ejecución, contraer las obligaciones que sean necesarias para la liquidación, confección del inventario y balance de situación de la fundación a fecha de inicio del procedimiento de liquidación y formar el oportuno balance de liquidación terminadas las operaciones.

Ahora bien, como anteriormente indicamos, se plantea el problema de que el art. 39 del reglamento no prevé que la liquidación de la fundación extinta pueda realizarse por el protectorado y, en el caso de que sea éste el que ejerce sus funciones por mor de lo dispuesto en el art.35.1.g) de la Ley, se requiere de la existencia de un patronato que no está y que no se ha sustituido, pues no se ha ejercido la previa acción de responsabilidad contra los patronos que figuran.

Una primera solución, de corte intervencionista, sería entender que como quiera que el protectorado debe controlar la liquidación, en suma, ante la ausencia de patronato y ejercido de derecho el gobierno fundacional por el protectorado, será él mismo el competente para adoptar las acciones anteriores, sin perjuicio de la posibilidad de impugnarlas por quienes estén legitimados para ello.

Como segunda posibilidad cabría entender que el protectorado ejerza el patronato por vía indirecta, designando gestores para la liquidación bajo su responsabilidad ${ }^{49}$. Este patronato de facto y ad hoc —al modo de los liquidadores de una sociedad mercantil — puede acordar las medidas de liquidación oportunas, el protectorado aprobarlas y que el juez decida en caso de desacuerdo o de que alguien legitimado para ello así lo inste.

Otro cauce posible podría ser solicitar del juez, en ejecución de la extinción (que legalmente conlleva la liquidación ex art. 33.1 de la Ley), que asuma la liquidación dentro del proceso de extinción, bien personal-

${ }^{48}$ La Ley 10/2005, de 31 de mayo, de Fundaciones de Andalucía, lo establece en su art. 43; la Ley 13/2002, de 15 de julio, de Fundaciones de Castilla y León, lo prevé en su art. 31; la Ley 8/1998, de 9 de diciembre, de Fundaciones de la Comunidad Valenciana, lo dispone en su art. 26; la Ley 12/2006, de 1 de diciembre, de Fundaciones de Galicia, lo recoge en su art. 46, y la Ley 1/2007, de 12 de febrero, de Fundaciones de La Rioja, lo contempla en su art. 40.

49 Vid. nota 37. 
mente con apoyo del protectorado, bien designando patronos a tal fin, o incluso al protectorado. Cabe que el juez entienda que una cosa es la extinción y que otra es la liquidación, y que deniegue por ello el proceso ejecutivo, obligando al uso de otros cauces, en esencia, tendentes a sustituir legalmente el patronato ausente para que sea el nuevo el que liquide, si bien lo propio sería que acordase lo procedente en ejecución de la sentencia de extinción —y a la larga de liquidación - dictada al efecto ${ }^{50}$.

Ninguna de estas tres opciones se contempla en ley y reglamento de modo expreso, mas la práctica permite acudir a cualquiera de las tres, si bien resulta recomendable la primera, por economía procesal y de medios, y más teniendo en cuenta que en última instancia es la Ley (art. 33.2 in fine) la que deja en manos del protectorado la decisión última sobre el destino de los bienes, bien por vía de impugnación judicial o en el caso de no haber patronato o no tener éste facultades conferidas por el fundador para decidir este destino. Siempre, eso sí, bajo la pertinente supervisión judicial o el amparo por vía jurisdiccional de quienes puedan verse perjudicados por estas decisiones y estén legitimados para actuar contra las mismas.

\section{CONCLUSIONES}

El extenso estudio acometido permite evidenciar que la causa extintiva de fundaciones consistente en que éstas no puedan acometer el fin para el que fueron constituidas presenta un enorme abanico de posibilidades prácticas en cuanto a su aplicación y consecuencias que, en gran medida, sólo pueden resolverse atendiendo a las concretas circunstancias de cada supuesto.

En cualquier caso, cabe entender que la imposibilidad concurre si la estructura fundacional no puede atender los fines para los que se creó o si, de mantenerse, los desdibuja hasta el punto de hacerlos irreconocibles. Lo esencial en la aplicación de esta causa es que el patronato ejerza con corrección y celo sus funciones para apreciar su concurrencia, que tales funciones se ratifiquen o suplan por el protectorado en lo que proceda, y que sea la autoridad judicial la que, caso de conflicto, provea lo procedente.

En cuanto al protectorado, su intervención activa, no la meramente ratificatoria, sólo debe producirse cuando, tras agotarse todos los cauces posibles que el ordenamiento ofrece, no resulte conveniente a los fines de interés general que debe proteger el mantenimiento a ultranza de la fun-

${ }^{50}$ Opción que, antes vimos, se adoptó por un Juzgado de Valencia. 
dación, pues cabe entender que en el ánimo del legislador prima la pervivencia de la misma sólo en tanto en cuanto los fines que persiga se conserven, de modo que es sobre el correcto cumplimiento de éstos donde reside la cuestión de si procede la intervención administrativa en asuntos que, en principio, deben ser puramente privados.

El efecto esencial de la aplicación de esta causa es, como de la de cualquiera de las otras extintivas previstas, la liquidación, y dentro de ella la parte más difícil de solventar es el destino que debe darse a los bienes de la fundación. Cabalmente, tal destino no debe ser el que vuelvan al fundador que se desprendió de ellos, sino que se dirijan a entidades o instituciones que presenten fines análogos, con la mira puesta en que, al menos de modo indirecto, puedan seguir cumpliéndose los fines de interés general para los que se creó la fundación originariamente.

Por ende, la liquidación se enfrenta al problema de que el patronato no esté o no actúe, en cuyo caso el ordenamiento ofrece cauces para que la lleve a efecto el protectorado, si bien no puede dejar de hacerse notar que existen vacíos normativos que aconsejan alguna precisión al respecto. 